\title{
Hybrid BIMASGO approach based optimal scheduling of renewable microgrid with multi-period islanding constraints
}

\author{
Kavitha Kumari $\mathrm{KS}^{\mathbf{1}^{*}}$ and Samuel Rajesh Babu $\mathbf{R}^{2}$ \\ Research Scholar, Electrical and Electronics Engineering, Sathyabama Institute of Science and Technology, Chennai, \\ India $^{1}$ \\ Associate Professor, Electronics and Communication Engineering, Saveetha School of Engineering,Saveetha Institute \\ of Medical \& Technical Sciences, Chennai, India ${ }^{2}$
}

Received: 19-May-2021; Revised: 14-July-2021; Accepted: 20-July-2021

(C)2021 Kavitha Kumari KS and Samuel Rajesh Babu R. This is an open access article distributed under the Creative Commons Attribution (CC BY) License, which permits unrestricted use, distribution, and reproduction in any medium, provided the original work is properly cited.

\begin{abstract}
In this manuscript, a hybrid system for the optimal microgrid programming with multi-period island constraints was proposed. The proposed hybrid method is the combined execution of the Buyer Inspired Metaheuristic Optimization Algorithm (BIMA) and Shell Game Optimization (SGO); hence it is named as BIMASGO approach. The BIMASGO approach was utilized for optimal microgrid programming and also considerably diminishes the computational load. The main objective of the proposed work is to diminish the cost of operating the microgrid, including the cost of operating the dispatchable units, the cost of transferring power from the main network, and the cost of inconvenience incurred by consumers. The cost of power transfer from the main grid should be positive or negative based on the direction of flow in the transmission line connecting the microgrid to the main grid. A negative cost represents an export of energy to the main grid, appears as an economic benefit for the microgrid. The cost of inconvenience represents the penalty in scheduling adjustable loads outside of consumer-specified time intervals. The constant penalty factor is utilized to prioritize loads with respect to sensitivity when operating at specified time intervals, where a higher value for the penalty factor denotes less flexible load based on time interval settings of the operation. The value of the penalty factor is chosen reasonably higher than the generation cost of the units and the market price. In the proposed system, the BIMASGO approach develops the evaluation procedure to establish the exact schedule of the microgrid combinations depends on the load side of the power range. In the proposed technique, the objective function is defined by the data of the system subject to equality and inequal ity restrictions. During the programming process, several actual constraints associated with adjustable charges, battery charge/discharge limitations, and the on/off time of dispatchable Distributed Energy Resources (DERs) were considered. The proposed method was implemented in the MATLAB / Simulink site. It was analysed and compared with different existing methods. The calculation time of BIMASGO and the existing methods were also discussed. The calculation time of the proposed method was 4.1 seconds.
\end{abstract}

\section{Keywords}

Microgrid, Scheduling, Constraints, Buyer inspired meta-heuristic optimization algorithm, Shell game optimization, Operating cost.

\section{Introduction}

In the distribution system, the microgrids were introduced to enable that emergence of abundantly Distributed Energy Resources (DERs). It is introduced to solve current energy, economy and environmental challenges by creating smart power grids [1]. Microgrid is small-scale power system.

\footnotetext{
*Author for correspondence
}

It is technically self-distributed with islanded capability that gives local intelligence supplied to the power system for supplying loads reliably and economically [2]. Microgrid presents individual chances in the power system functioning and scheduling. It enhances dependability by introducing autonomous-healing in the network of local distribution. It is also helpful in minimizing the feasibility of load shedding by maintaining local loads [3], decreasing carbon emissions via diversifying energy sources, economic mode using diminishing the transmission with distribution costs [4]. It provides 
energy efficiency through responses to real-time market prices, lessening that overall system cost by deferring investments on novel generation and transmitting conveniences [5].

The microgrids salient feature is its capacity for islanding from the major power supplying network [6]. The islanded is generally made to quickly detach the microgrid from error supply network in order to protect the microgrid modules from upstream instability and to provide persistent loads [7]. This is done to secure the loads of voltage sensitive from noteworthy voltage drops, where lack of instant solution for main grid voltage problems. The microgrid is operated economically in the mode of grid connected [8]. Nevertheless, the adequate capacity can always obtain if microgrid is desired to switch islanded. In point of common coupling, the microgrid is islanded as main grid utilizing upstream switches, and then the microgrid load is totally delivered using local resources [9]. In grid-connected and islanded modes, the microgrid scheduling is activated by the microgrid master controller depending on economic with secure conditions [10]. The master controller defines the microgrid communication along with the main grid. The decision of switching amid the grid-connected and islanded, as well as optimum local resources [11]. The microgrid optimum scheduling enabled through microgrid master controller is significantly varied from the unit commitment issue addressed using Independent System Operator (ISO) for main grid [12]. Owing to its significant size likened to local loads the resources of variable generation and Energy Storage System (ESS) are significant parts of microgrid [13]. Besides, generation resources near to load position, then power is transmitted over medium or less voltage supplying networks, therefore, blocking in power transmission is not an issue [14].

The higher local load percentage can be responded to differentiate the that creates load/generation balance of microgrid is flexible [15]. In grid connection mode, the main grid connection denotes the main grid from infinite bus using unlimited power distribution; it allows lessening power mismatches on the microgrid by transferring power [16]. The main grid provides reserve for the microgrid while the forecasted variable generations do not materialize or load prediction errors are maximum [17]. Notwithstanding, in the main grid the optimal microgrid scheduling and unit commitment issue share a general goal, that is to define the lowest cost functioning of resources obtainable for distributing predicted loads, deeming the prevailing operational constraints [18]. They share a general goal, the aforementioned differences do not allow direct usage of existing unit commitment strategies for the optimal programming of microgrid issue [19]. The quick advancement of microgrids requires novel techniques for elaborating the entire active components of microgrid. It focused on microgrid islanded, especially when the main grid power is not obtainable [20].

Microgrid programming was carried out by a master controller connected to the network, including the islanded. The master controller defines that optimal transmit and transferred the power of DERs in the middle of the microgrid and the utility of distributing by Point of Common Coupling (PCC). It lessens the total cost of operation under technical, reliability and operational restrictions. Substantial efforts have been made for optimal scheduling and microgrid management [21].

Scheduling models for microgrid in islanded mode are presented in [22]. Notwithstanding, much explore and published works are dedicated to microgrid programming in network connected mode [23]. Deterministic approaches were used when generating stochastic programming modes in [23]. The indecision management of future electrical systems to maintain that the intermittency of wind energy is expressed in [24]. In the literature, scheduling modes show the reduced version of unit commitment issue of bulk power systems. It was defined as the lowest cost dispatch of obtaining resources to fulfill that predicted requirements when prevailing operational constraints is met [25]. However, the microgrid scheduling problem varies substantially as unit commitment issue owing to the unique characteristics of microgrid.

The main characteristics of microgrid are capability to divide as a distribution service to continue supplying loads on their own portion of the islanded. The transition of the microgrid as grid-connected to is olated mode is generally linked to extreme load. This is mostly due to the fact that energy exchanged among microgrid and the distribution network through the PCC is forced to zero. This can happen due to poor load programming, wrong renewable generation forecast, etc. Thus, the main variance among unit commitment and microgrid programming is microgrid islanded requirements. Furthermore, renewable generation sources and energy storage systems play an important role in the operation of the microgrid based on its significant size likened to local loads [26]. Owing to restricted capacity and proximity of load and 
generation under microgrid, the network is often not the constraint. The fundamental importance to develop a novel microgrid programming approach capable into account the islanded capacity of microgrid and the probabilistic characteristics of the load and renewable energy. Consequently, the programming of microgrids with islanded capacity limitations has lately been proposed [26].

In [26], an optimal microgrid programming model has multi-period islanded restrictions were suggested. This model makes sure that adequacy of microgrid generation under the islanded mode of specified duration in the event of unforeseen disconnection as main grid. A novel concept based on probability, Probability of Self-Sufficiency (PSS), was introduced to specify that probability of microgrid will be able to satisfy local demand on islanded mode. The probabilistic balance of power restriction is recreated in mixed-integer linear form and clearly involved in the microgrid programming model. In [27], a probabilistic methodology is proposed to estimate the rotating reserve demand under microgrid. The particular characteristics of microgrids, like islanded capacity, have been neglected. Furthermore, in [27] only the ascending reserve is as sumed. The generation on the microgrid after islanded installation is common and significant problem, assuming the ownership of generation resources on microgrid.

Generally, the master controller enables microgrid programming in grid-connected together with isolated modes. The master control measures that optimal DER transmit and power transformation at the microgrid and the distribution company through PCC, reducing the total operating cost under several technic, reliability and operational restrictions [21]. In [22] programming methods for microgrid in islanded modes were proposed. Many studies and published works were dedicated to microgrid programming in network-connected mode [23]. Especially deterministic models were represented in [23], as stochastic models. The stochastic / robust scheduling approach was introduced for microgrid programming. Managing the uncertainty of future power systems and approaches to maintaining intermittency of wind power is implicit in [24]. At previous bibliography, programming models refer shortened version of unit commitment is sue under bulk energy systems. As both issues define the lowest cost delivery of obtaining resources to fulfill the intended requirement while fulfilling the constraints prevailing operational [25].

\section{Objectives and Contribution}

- A hybrid method with multi-period islanding restrictions was introduced and proposed for scheduling the microgrid optimally.

- The proposed study is helpful to solve the optimization issue. It is a combination of Buyer Inspired Meta-heuristic optimization Algorithm (BIMA) and Shell Game Optimization (SGO); hence it is named as BIMASGO approach.

The remaining sections of this manuscript are structured in the following way. Section 2 presents current literature investigation with their background. Section 3 illustrates that structure of the proposed system and its modelling. Section 4 illustrates the proposed BIMASGO based optimal scheduling modelling in microgrid along multi-period islanding constraints. Section 5 demonstrates the simulation outcome of the proposed approach and its discussion. Section 6 concludes the manus cript.

\section{Literature review}

Rokni et al. [28] have suggested the Alternating Direction Method of the Multiplier (ADMM) for the energy management distributed system. The combined central and local controller's schedule was the major concern of the introduced approach. The distributed energy management is sue was assumed as the optimal power flow issues. The microgrid and the efficacy of the proposed system were analyzed by the introduced approach.

Ebrahimi and Amjady [29] presented the adaptive robust optimization model for scheduling the microgrid with reduced cost. Three level optimization schemes were used by the introduced approach in microgrid. The third level was the selection of resources in the microgrid system.

Vahedipour-Dahraei et al. [30] suggested the stochas tic dis patch model for demand response actions in a microgrid circumstance. Based on the demand response the scheduling of the security-constraint was determined. The islanded suburban microgrid was chosen by the introduced approach. Under the uncertainties of load, including renewable energy sources reservations introduced approach was processed in which increased the predictable profitability of the microgrid operator then reduces the total customer expenditure for electricity utilization. The mixed-integer programming and general algebraic modeling were utilized to model the cost based demand response. Through the switching as well as 
inimization of the load, the customer was playing a part in the real-time pricing method.

Kiptoo et al. [31] have suggested integrated planning model for analysis the techno economic performance of the microgrid with renewable energy resources. The introduced approach microgrid incorporated with wind turbine, photovoltaic, diesel generator, etc. The introduced system was modelled by the mixed-integer linear programming algorithm. The major purpose of the introduced approach was minimization of overall system cost which incorporated with annual costs, running costs, cost on demand side management. The introduced approach maximizes the flexibility through the balancing of generation and load demand.

Banaeia and Rezaee [32] developed a fuzzy scheduling model for developing process of nonis olated micro-grid cost. The introduced approach was taken the uncertainties like predicting outcomes of renewable resources, fuel cell, battery maximal efficiency, distributed line higher ability, hourly requirements for planning the cost-based operation of microgrid. These uncertainties were modeled by the fuzzy set and optimal planning was obtained by the three levels of optimization.

Gazijahani et al. [33] suggested epsilon-constraint approach for the scheduling and risk management of the microgrid. Because of the uncertainty and variability of the sources the microgrid reserve planning was complicated. To schedule the microgrid, the introduced approach was utilized the stochastic cost-emission based approach. The major purpose of the introduced approach was the scheduling of microgrid, increasing the social welfare, reduces the environmental emissions of the microgrid.

Kumar et al. [34] have suggested 3-level stochastic Energy Management Systems (EMS) for resolving the optimum day-ahead planning and reducing the cost of the microgrid connected system. The first level of the suggested approach was dataset generation and the second level was system configuration with specified constraints. The quantum particle swarm optimization was used for the third level of the system operation which increases the power given to the grid.

Wei et al. [35] presented the multiple period planning is sue of multiple energy microgrids deeming that longterm and short-term uncertainty. Kumari and Babu [36] provided a proficient method for deeming optimum microgrid scheduling with islanding constraints. Sefidgar-Dezfouli and Davatgaran [37] explained 2-stage scheduling approach to define the needed reserve for stable islanding assuming uncertainties of load and renewable generations. Aghdam et al. [38] illustrated that randomized constrained scheduling is used for daily scheduling of multi-microgrid system at uncertain environment. Lee et al. [39] have elucidated the problem of optimizing that performance of microgrid under the context of uncertain islanded events. Hemmati et al. [3] introduced an innovative, optimal approach for programming reconfigurable microgrid programs assuming potential islanded restrictions. VahedipourDahraie et al. [40] have explained a stochastic structure of the optimal microgrid schedule, assuming non-scheduled islanded events, initiated by disturbances under the main network. Jafari et al. [41] studied an electricity market approach for optimal functioning of multiple microgrids (MMG). Lei et al. [42] have proclaimed a problem of allocation and planning of resources of the defense of microgrid with the deliberation of attacks of multiple periods. Sefidgar-Dezfouli et al. [1] portrayed numerous randomly restricted scheduling modes evolved for the optimal microgrid schedule, assuming significant factors affecting microgrid power balance, requirements uncertainty, renewable resources, unexpected outage of distributed generators, unnecessary islanded. Yixin Liu et al. [43] introduced multiple period investment planning mode was presented for supporting decision-making to stakeholders in computing that optimal size as well as investment timing of distributed energy resources of is landed microgrid.

The recent investigation works show that optimal planning of microgrid with islanded controls is a necessary requirement of the current trend. In the islanding function of microgrid the energy storage system plays a major role. One of the difficult tasks of the EMS is calculating the size of photovoltaic, wind, diesel generator. In the microgrid system, the EMS including price factors minimization of the microgrid scheme is the significant work. To solve the problems like instability emanating from renewable resources along difficult relationship amid load requirement and factors, many approaches was introduced in the recent days. Some of the approaches are fuzzy, Neuro-fuzzy and optimization algorithms. Fuzzy Logic Controller (FLC) offers better outcomes; however, it has not implied the uniqueness of the fuzzy systems theory. Besides, Particle Swarm Optimization (PSO) has proven optimal global search capability. Though, the PSO approach, the velocity equation has random variables, hence the universal finest value varies 
uncertainly. Consequently, Renewable Energy Source (RES) control models were majorly modeled for monitoring the requested power, make optimal energy source usage, then regulate the direct current bus voltage in the microgrid connected system.

In grid-connected, microgrid schedule with islanded modes is activated by the microgrid master controller depending on security, including financial considerations. The master controller defines the interaction of the microgrid with the main network, the decision to switch amid the network and islanded modes, ideal operation of local resources. Optimal micro network programming enabled through the microgrid master controller varies significantly from unit compromise is sues solved via ISO to the main net. In the microgrid function, variable generation resources together with ESS are a vital part due to their significant size compared to local loads. In addition, the generation resources have been close to the load facilities, then the energy is transmitted through distribution networks of medium or lower voltage, so that congestion is not a complexity in the energy exchange. A higher percentage of local loads responds to price fluctuations, making the microgrid load / generation balancing more flexible. In grid-connected mode, the main grid link means the main grid is an infinite bus with unlimited power supply/ requirement. It realizes a power mismatch reduction in microgrid by exchanging power from the main network. When the predicted variable generations do not work or the load forecast errors are maximized, the backbone can also provide the presence of microgrid. However, the optimal programming of microgrid with the problem in the main network share a common goal, that is, to measure the least cost function of the resources obtainable for the provision of predicted loads by considering the prevailing operational constraints. The rapid growth of microgrids requires novel ways of making all the real components of microgrids and is focused on the needs of the microgrid islanded, especially when power cannot be obtained from the main grid. Optimal microgrid programming is widely studied in the literature. The previous EMS architectures for microgrids have been examined, in which centralized with distributed modes are recognized as a general microgrid control method. The centralized mode, gathers total required information to microgrid scheduling as well as activates centralized process and control. At distributed mode, every module is deemed into agent along distinct decision making capability. The optimal schedule has been acquired by iterative data transmit among the agents. Both control models provide advantages with disadvantages, but the centralized mode is highly desirable as it guarantee the safe microgrid process as well as appropriate for optimization technique's application. The major disadvantages of centralized mode are diminished flexibility, including newly components and extensive computational requirements.

The major limitations found in the previous study are as under:

- Traditional methods impose a high computational burden to system for energy management.

- Effect of electrical networks and power flow equations were not considered in the previous works and all units and loads were jointly connected to a common bus in a microgrid.

- This huge amount of data exchange between customers and the control center may cause to congestion in the communication network.

- The customers may not relief to jeopardize their privacy by making public detailed information on their loads and preferences.

- Methods based on deterministic optimization were unable to address the problem's uncertainties.

- It is difficult to determine the probability distribution functions of some uncertain parameters, e.g., due to lack of sufficient historical data.

- A large number of scenarios may be needed to properly describe the uncertain parameters in a stochastic model, which increases the computational burden.

- Previous models do not consider the individual aspects of microgrid operation like islanding capability.

- Some techniques suffer from lack of confidence while moving towards the global optimum. There is a chance that those techniques can stick to a local optimum.

- The importance of individual appliance scheduling Demand Side Management (DSM) technology was not explored in the field of microgrid operation.

- Although less conservative for most realizations of the random variable, traditional approaches may lead to constraint violation if knowledge of distribution is inaccurate or if extreme realizations of the random variables occur.

- The power fluctuations resulted in microgrid operation may negatively impact the power balance within the microgrid.

- The primary drawback of current approaches was the impact of operation mode. Switching is not adequately addressed in the scheduling process, 
which oversimplifies the scheduling problem to a scaled-down unit commitment problem.

- The provision of reserve before and after islanding was not considered in the previous work.

- The high computational burden is also a major factor for the energy management.

To address the various challenges presented by the existing systems, the present study demonstrates and incorporated microgrid system for handling the current challenges proficiently.

\section{Methods}

Figure 1 portrays that overall framework of the proposed system. In the microgrid scheduling issue, different component of the microgrid such as ESS, distributed energy resources, local generators and various kinds of loads. There are two categories of loads are used in the proposed model like adjustable load and fixed load. Based on the cost or islanding need, the adjustable loads are modified or shortened. In the system, while the fixed load if it is present or not, it cannot change or curtailed [44]. The generating unit consists of disposable unit and non-disposable unit. The operation of dis patchable part is based on the constraints and the non-dispatchable unit part is based on the intermittent nature.

The important part in the microgrid is the energy storage system which is operated based on the charging and discharging modes. When the load is greater than the production and market price is high, then it operates under the discharging mode. When the load is low and price also low, then it operates under the charging mode. It is used to shift the load of the system. The microgrid provides two kinds of operation like grid connected mode, is landed mode of operation. In the BIMASGO model, major contribution is cost minimization. The microgrid was scheduled based on the operation of microgrid and the proposed approach.

\subsection{Operation under the grid-connected mode}

The grid connected operation mode considered the optimal connection of the main grids as well as transmit of the disposable units. In this mode, the adjustable load scheduling and the quantity of power transfer as main grid with charging and discharging plan of ESS were determined. The adjustable load scheduling was measured by the main grid power transformation. The key intention of the proposed method was to diminish that system cost. The operating cost of the proposed system was considered as the sum of cost of disposable units from the main grid. The dispatchable unit cost includes the cost of generation, startup and shutdown costs.

Under the grid connected mode the intention function is described as shown in Equation 1.

$$
O B J=\min \operatorname{Cost}=\operatorname{Min} \sum_{k} \sum_{i \in d g}\left[G_{i}\left(P_{i k}\right) C_{i k}+s u_{i k}+s d_{i k}\right]+\sum_{k} C_{m k} P_{m, k}+\sum_{l \in L} p f_{l} \Delta_{l}
$$

Here, $i$ denotes the index of DERs, $k$ denotes index time, $d g$ denotes dispatchable units, $l$ denotes loads, $L$ denotes adjustable load set, $G$ denotes generation cost, $P$ denotes DER output power, $C$ denotes ESS position, $\boldsymbol{s u}$ denotes start-up cost, $s d$ denotes shut down cost, $C_{m}$ denotes market price, $P_{m}$ denotes main grid power, $p f_{l}$ denotes difficulty penalty factor and $\Delta_{l}$ denotes deviation on adjustable load operating time. Depending upon the direction of power flow in transmission line which is linked microgrid to the main grid, the cost of power transfer is negative or positive. Economic benefit was considered as the negative cost in which power is transferred to the main grid. The inconvenience, cost means the penalty cost. It means penalties for planning modifiable loads outside of time intervals with consumers. The proposed system was used the stable penalty factor. It was utilized to prioritize the loads based on sensitivity within certain time intervals. Within the time interval, if the penalty factor is high, then it signifies a less flexible load. The penalty factor was selected randomly, in which it is greater than the unit production cost with market price.

\subsection{Operation under the islanded mode}

Islanded mode operation was used to check the availability of adequate power generation of microgrid and to ensure uninterrupted supply for loading. When the power generation of microgrid was not enough the operation of islanding is not possible. It indicates that the local load is not getting power from the microgrid [45]. So, the mismatch problem islanded mode is addressed by the re-adjusting the ESS and grid connected generation scheduling system. The proposed approach uses the cut 1 and 2 for solving the mismatch issue and constraints. It's also capable of solving the mismatch is sue.

3.3Constraints of the proposed microgrid system The set of equality and inequality limits are used to solve the issue of scheduling of microgrid which is described below. 
Kavitha Kumari KS and Samuel Rajesh Babu R.

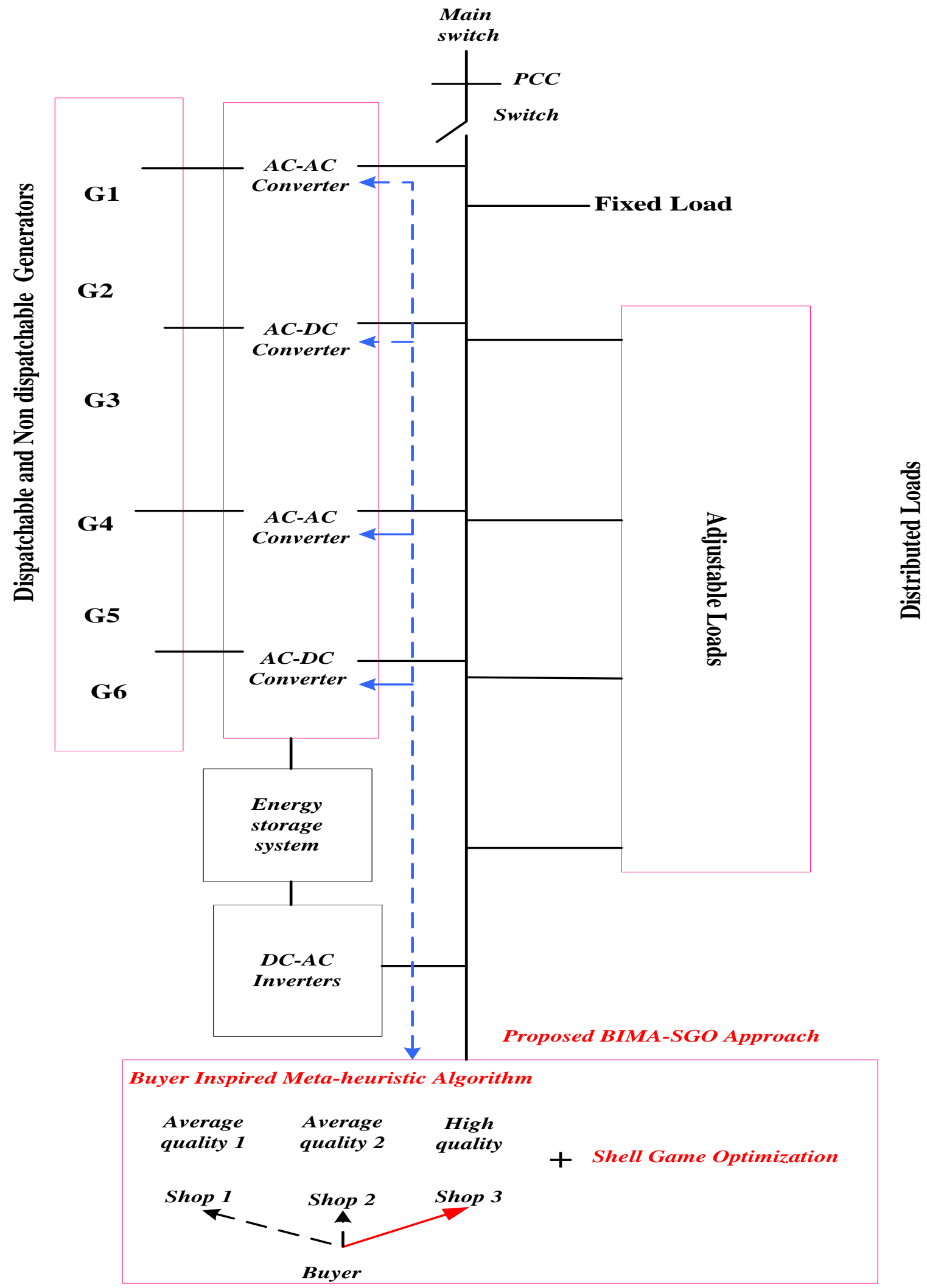

Figure 1 Overall structure of the proposed system

830 
3.3.1 Equality constraints

\section{-Constraint of power balance}

To fulfill the power requirement power balancing is a significant factor. When balancing the system power, it provides system safety with minimized cost. The power balance ensures that the sumof power produced by the units and power coming as energy storage devices. It shows the power transmission as a main grid to match the existing hourly loads (Equation 2).

$\sum_{k} P_{\text {gout }, t}+P_{\text {mout }}=\sum_{e} L_{e t} \forall t$

Here, $P_{g \text { out }, t}$ indicates power generated by the generated units depends on time, $P_{\text {mout }}$ indicates power transmission from the main grid and $L_{e t}$ indicates existing load.

3.3.2 Inequality constraints

- Load balance constraints

It describes the sum of power generated utilizing DERs with main grid power could match the load per hr. (Equation 3).

$$
\sum_{k} P_{k t}+P_{M, t}=\sum_{l} L d t \quad \forall t
$$

\section{- Power generation}

The transmission of power via the main grid is constrained with flow restrictions of the line linking the microgrid to main grid direction (Equation 4).

$$
-P_{m}^{\text {Min }} \leq P_{m, t} \leq P_{m}^{\text {Max }} \forall t
$$

\section{- Dispatchable unit generation}

This is deemed as minimal with maximal generation efficiency limits (Equation 5).

$$
P_{k}^{\text {Min }} C_{k t} \leq P_{k t} \leq P_{k}^{\text {Max }} C_{i t} \quad \forall k \in G, \forall t
$$

-Ramp-up Rate

This is expressed as Equation 6.

$$
P_{k t}-P_{k(t-1)} \leq R_{u p, k} \quad \forall k \in G, \forall t
$$

Here, $R_{u p}$ denoted as ramp up rate.

\section{-Ramp-down Rate}

This is exhibited as Equation 7.

$$
P_{k(t-1)}-P_{k t} \leq R_{\text {down }_{k}} \quad \forall k \in G, \forall t
$$

Here, $R_{\text {down }}$ denoted as ramp down rate.

\section{-Minimum-up Time}

This is mathematically exhibited as Equation 8. $T_{k}^{o n} \geq u t_{k}\left(C_{k t}-C_{k(t-1)}\right) \forall k \in G, \forall t$

Here, $T^{o n}$ signifies count of subsequent ON hours.

-Minimum-down Time

This is mathematically exhibited as Equation 9.
$T_{k}^{o f f} \geq D T_{k}\left(C_{k(t-1)}-C_{k t}\right) \forall k \in G, \forall t$

Here, $T^{\text {off }}$ denotes count of continually OFF hours. A

state of unit committed represents 1 when the unit is committed, else it represents 0 . The energy storage power implies +ve (discharge) or -ve (charge).

-Energy storage power (ESP)

The ESP is regulated using the minimum and maximum power constraints as shown in Equations 10-12.

$$
\begin{aligned}
& P_{k t} \geq P_{k t}^{\text {Dis,Max }} u_{k, t}-P_{k t}^{C h, \text { Min }} v_{k, t} \quad \forall k \in S, \forall t \\
& P_{k t} \geq P_{k t}^{D i s, \text { Min }} u_{k, t}-P_{k t}^{C h, M a x} v_{k, t} \forall k \in S, \forall t \\
& u_{i, t}+v_{i, t} \leq 1
\end{aligned}
$$

here $S$ denotes set of ESS, $u$ denotes energy storage discharge state, $v$ implies energy storage charge state.

-State of Charge (SOC) of energy storage

The quantity of power charge, discharge, and constrained based the level of energy storage is measured by ability constraints (Equations 13 and 14).

$S O C_{k t} \geq S O C_{k(t-1)}-P_{k t} \forall k \in S, \forall t$

$0 \leq S O C_{k t} \leq S O C_{k}^{M a x}$

Here, the state of charge of energy storage is denoted as $S O C$.

-Minimum charge and discharge time limits

Energy storage was also considered for the number of consecutive hours required to maintain theiroperating mode (Equations 15 and 16).

$$
\begin{aligned}
& T_{k}^{c h} \geq c h_{\min k}\left(u_{k t}-u_{k(t-1)}\right) \quad \forall k \in S, \forall t \\
& T_{k}^{d c h} \geq \operatorname{dis}_{\min k}\left(v_{k t}-v_{k(t-1)}\right) \quad \forall k \in S, \forall t
\end{aligned}
$$

here $T^{c h}$ and $T^{d c h}$ as count of consecutive charge and discharge hours respectively, $c h_{\min }$ as minimum charge time, dis $s_{\min }$ as minimum discharge time. The minimum with maximum rated powers is subject to adjustable loads, and it uses the essential power to complete an operating cycle with the consumer at specified intervals (Equations 17 and 18).

$$
\begin{aligned}
& L_{l t}^{\min } z_{l t} \leq L_{l t} \leq L_{l t}^{\max } m_{l t} \quad \forall l \in L, \forall t \\
& \sum_{t \in\left[\chi_{l}, \delta_{l}\right]} L_{l t}=E_{l} \quad \forall l \in L
\end{aligned}
$$

Here, $E$ implicates overall load energy requirement, $m_{l t}$ implicates modifiable load condition, $\chi, \delta$ signifies specific start and stop times of modifiable load. 


\subsubsection{Constraint of resilient operation}

The resilient operation problem for islanding state is described as Equation 19.

$$
O B J_{\text {resilient }}=M_{U} \underset{U}{ } \operatorname{Min}_{V} \mathrm{pm}_{s}=\sum_{t}\left(S l_{1, t s}+S l_{2, t s}\right)
$$

Here, $U$ and $V$ denotes set of uncertain parameters, and primal variables respectively, $\mathrm{pm}$ implies power mismatch, $S l_{1}, S l_{2}$ implies lack variables. In the general operation, the change of power is described as Equation 20.

$\left|P_{k t s}-\hat{P_{k t}}\right| \leq P_{a d j}$

Here, permissible power adjustment is denoted as $P_{a d j}$ 3.3.4 Consideration of uncertainty

The uncertainty parameters are used for flexible operation of non-dispatchable generation and load. Based on the powerbalance it is described as Equation 21.

$$
\sum_{k G} P_{k t}+\sum_{k \in W} \underline{P_{k t}}+S l_{1, t}+S l_{2, t}=\sum_{l \in L} L d t+\sum_{l \notin L} \bar{L} d t \quad \forall t(21)
$$

The power limit under is landing mode is described as Equation 22.

$$
-P_{m}^{\text {Max }} U_{t s} \leq P_{m, t s} \leq P_{M}^{M a x} U_{t s} \quad \forall t
$$

The inactivation level of microgrid is land represents a zero value on main grid power. The system function is checked depending on the resilience cut (Equation 23).

$$
\hat{w}_{s}+\sum_{k \in G} \lambda_{k t s}\left(C_{k t}-C_{k t s}\right)+\sum_{k \in S} \mu_{k t s}^{d c h}\left(u_{k t}-u_{k t s}\right)+\sum_{i \in S} \mu_{k t s}^{c h}\left(v_{k t}-v_{k t s}\right)+\sum_{k \in L} \pi_{k t s}\left(z_{l t}-z_{l t s}\right) \leq 0
$$

The energy saving, adjustable load adjustment and unit commitment levels were verified in the case of islanded non-reachability.

\subsection{Proposed BIMASGO based optimal scheduling modeling in microgrid with multi-period islanding constraints}

In this manuscript, a hybrid method including multiperiod islanding restrictions was proposed to schedule that microgrid optimally. The proposed system was considered the grid connection with is landed mode of operation. For checking that the optimum generation of power and uninterrupted supply, the islanded operation was used. If the grid does not give the power of local load sufficient, then it goes to Bender's cut 1 , then the scheduling operation is given to the grid connection.
The power mismatch in islanding problem was represented by the bender cut 1 . It is reduced by energy storage and generation rescheduling. The Bender's cut 2 is used to adjust the load scheduling when the ESS together with unit commitment has not provided the viable islanding. If these checks satisfied with the power generation condition, then the BIMASGO process for solving the cost optimization and scheduling were initiated. First the BIMA was processed to obtain the best data set generation. Then the outcome was processed by the SGO approach.

3.4.1 Data set generation using buyer inspired metaheuristic optimization algorithm (BIMA)

BIMA stimulated by human social behavior when searching and negotiating products. At BIMA, the exploration as well as exploitation is accomplished using store-to-store hoping with negotiating products for purchasing, depending on cost, product quality, selection and distance to the store. The major motivation of this approach is negotiator or buyer trying to buy the optimum product from the dissimilar count of stores obtainable at market [46].

A group of negotiators / buyers were deemed as a swarm. To get the optimum product the buyer can move one store to another based on the diverse parameters and equivalent fitness value. The outcome was utilized by other buyers to get the optimum store. The scenario of worst-case for a buyer, when purchasing a product was computed from the storage position. It is based on price and quality. The worst buyer position is utilized to prioritize the selection factor. When optimizing the position mode to the best overall position, a buyer must evade the worst position in the respected space. The stores are distributed randomly in a particular search space, also hypothetically position close to the buyer's position. Normally, all buyers prefer to shop in nearby stores. But to get maximal profit, and preferred product, still slightly, shoppers explore stores placed in greater distance depending on its reviews from neighboring shoppers. Here, BIMA is the major objective to get the optimum store (location on search space) that can offer the best quality product at an optimal price.

3.4.1.1S tep by step procedure of BIMA approach

Step 1: Initialization

Here, initialize that maximum iteration, number of search agent, upper and lower limit, and the population vectors.

\section{Step 2: Random Generation}

The population vectors are randomly generated by the Equation 24. 


$$
R_{p}=\left[\begin{array}{cccc}
P_{p s}^{11} & P_{p s}^{12} & \cdots & P_{p s}^{1 n} \\
P_{p s}^{21} & P_{p s}^{22} & \cdots & P_{p s}^{2 n} \\
\vdots & \vdots & \vdots & \vdots \\
P_{p s}^{m 1} & P_{p s}^{m 2} & \cdots & P_{p s}^{m n}
\end{array}\right]
$$

\section{Step 3: Fitness Calculation}

Calculate the fitness based on the objective of the proposed approach and evaluate the fitness value (Equation 25).

$$
O b j=\min \{C \text {, resilance }\}
$$

Then update the best fitness value and check the iteration. If the max iteration is not reached, then found the boundary.

\section{Step 4: Calculate the boundary}

The boundary of the population is calculated by the following Equation 26.

$$
\text { Rad }=\frac{U L-L L}{4}+\left[(U L-L L)\left(\frac{\text { iter }}{\text { max iter }}\right) \times 2\right]
$$

Step 5: Find the weight of the system The weight is calculated by Equation 27.

$$
W=0.9-\text { iter } *(0.9-0.4) / \text { iter }^{\text {Max }}
$$

If weight is calculated then assess the fitness function of the system, also upgrade the better value of the system.

\section{Step 6: Evaluate best and worst Case}

This is evaluated by Equation 28.

$$
\text { GBest }=\min (\text { pBest }), \text { Gbest } X=\arg (\min (p \text { Best })
$$

\section{Step 7: Updation}

Update the weight and state vector and position vector and check the boundary condition (Equation 29).

$$
X_{i+1}=X_{i}+\Delta X_{i+1}
$$

\section{Step 8: Termination criteria}

If the boundary conditions are satisfied means optimal solution is obtained otherwise go to step 3 .

3.4.1.2S GO for optimal scheduling

SGO is employed for the proposed methodology. The main advantage of SGO is no control parameters. So, there is no need to configure the parameters [46]. Suppose the game operator is a person. The operator contains 3 shells with 1 ball. In this game, the player has 2 chances to estimate the optimum shell. The proposed BIMASGO approach is used to schedule the microgrid operation and reduce the operating cost of the system.

3.4.2.1S tep by step procedure of S GO

\section{Step 1: Initialization}

The outcome of BIMA approach is given to the input of the SGO. The input vector is described in Equation 30 .

$$
X_{i}=\left[\left(V_{1}, P_{L 1}\right)^{1},\left(V_{2}, P_{L 2}\right)^{2} \ldots\left(V_{n}, P_{L n}\right)^{n}\right]
$$

\section{Step 2: Random formation}

Then randomly generate the input variable by using the Equation 31.

$$
x_{i}=\left(y_{i}^{1} \ldots, y_{i}^{d} \ldots, y_{i}^{n}\right)
$$

Here, the random variable of islanded event $x_{i}$, based on the value the fitness function is achieved.

\section{Step 3: Fitness Evaluation}

The fitness function is assessed by Equation 32. It represents the objective function.

$$
\text { Obj }=\min \{C \text {, resilance })
$$

\section{Step 4: Selecting three shells}

Based on the fitness function, three shells are arranged like one is best and the other two are randomly selected (Equation 33).

$$
\text { Operator }=\left\{\begin{array}{l}
S_{1}=\text { ball }=X_{b s t} \\
S_{2}=X_{r 1} \\
S_{3}=X_{r 2}
\end{array}\right.
$$

Step 5: Determination of accuracy and intelligence For each function objective is evaluated (Equation 34).

$$
A_{i}=\frac{f_{i t(i)}-f_{i t}\left(X_{\text {worst }}\right)}{\sum_{l=1}^{n}\left[f_{i t(l)}-f_{i t}\left(X_{\text {worst }}\right)\right]}
$$

\section{Step 6: Simulating the guess state}

The minimization along the maximization fitness result of each $X_{\text {worst }}$ is calculated as following guess vector Equation 35.

$G(x)=\left\{\begin{array}{l}S_{1}=\text { If } A_{i}>g_{1} \\ S_{2}=\text { If } A_{i}>g_{2} \\ S_{3}=\text { else }\end{array}\right.$

Here, correct guess for first selection is represented as $g_{1}$, correct guess for second selection is represented as $g_{2}$.

\section{Step 7: Updation}

Here, the updated value is represented as $d y_{i, b}^{d}, d y_{i, S_{2}}^{d}, d y_{i, S_{3}}^{d}$

If all parameters are updated, then go to the next step or else return to step 6 .

\section{Step 8: Termination}

If the stopping criteria met than find the optimum solution otherwise move step 2. Figure 2 shows the flowchart of BIMASGO algorithm.

Update the values of the values using the following Equation 36.

$$
y_{i}^{d}=y_{i}^{d}+d y_{i, b}^{d}+d y_{i, S_{2}}^{d}+d y_{i, S_{3}}^{d}
$$


Kavitha Kumari KS and Samuel Rajesh Babu R.

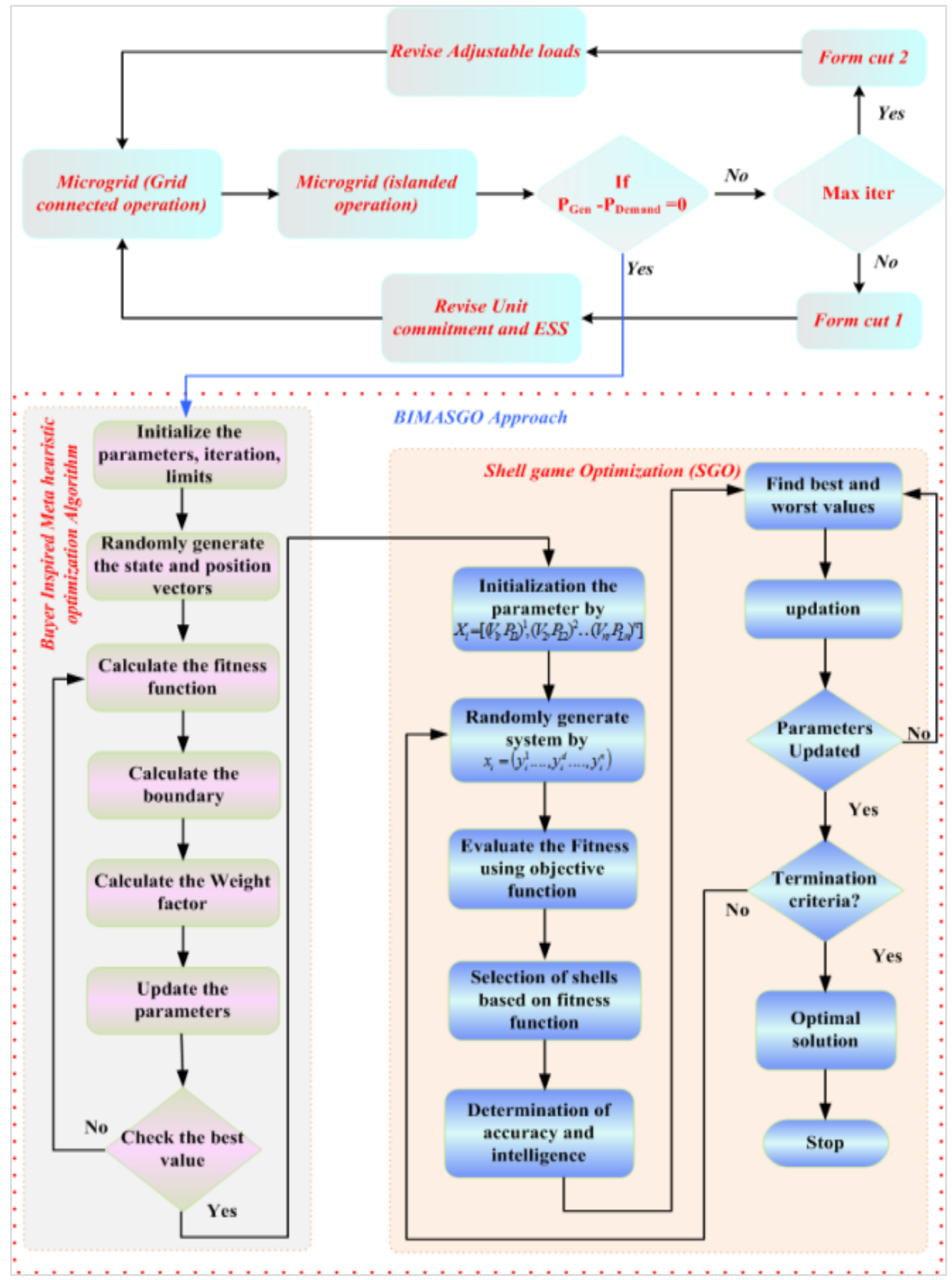

Figure 2 Flowchart of proposed BIMASGO algorithm 


\section{Results and discussion}

In this segment, the simulation outcome and the performance of the proposed BIMASGO approach was described. In this manuscript, a hybrid process along multi-period is landing constraints was proposed for scheduling the microgrid optimally. The BIMASGO approach was used to lessen the cost of the system which incorporates dis patchable units working cost and power export as main grid cost at consumer side (inconvenience cost). Based on the load demand, the microgrid was scheduled. At each hour the demand of the load is changing. The proposed approach was activated in MATLAB/Simulink site. The BIMASGO approach efficiency was likened to different existing algorithms like Firefly (FF), Gravitational Search Algorithm (GSA), Dragonfly Algorithm (DFA), Modified Dragonfly Algorithm (MDA), Cuttlefish Algorithm (CFA), Whale Optimization Algorithm (WOA), Crow Search Algorithm (CSA). The proposed approach was analysed under two cases. These are with grid and without grid mode. Implementation parameters of the proposed systemare shown in Table 1.

(1)The performance of the proposed technique is evaluated based on the optimal schedule of microgrid under grid connected mode and under is landed mode.

(2)The performance parameters like power and cost are also analysed.

(3)Percentage of energy created at microgrid under is landing mode operation ( $12^{\text {th }}$ hour and $15^{\text {th }}$ hour) and computation time was also analysed.

(4)Scheduling of adjustable load for grid connected mode and islanded mode were also analysed.

(5)Finally, the performance metrics like Root Mean Squared Error (RMSE), Mean Absolute Percentage Error (MAPE) and Mean Bias Error (MBE) were evaluated under large number of trails.

Table 1 Implementation parameters of the BIMASGO technique

\begin{tabular}{|c|c|}
\hline Implementation parameters & Values \\
\hline \multicolumn{2}{|l|}{ FF } \\
\hline Maximum number of iterations & 100 \\
\hline The number of firefly on population & 30 \\
\hline$\beta_{0}$ & 1 \\
\hline$\beta_{\min }$ & 0.3 \\
\hline$\varepsilon_{\mathrm{amp}}$ & 0.005 \\
\hline Dimension of population & 25 \\
\hline \multicolumn{2}{|l|}{ GSA } \\
\hline Dimension of issue & 04 \\
\hline Number of agents & 50 \\
\hline Maxiteration & 50 \\
\hline \multicolumn{2}{|l|}{ DFA } \\
\hline $\mathrm{B}$ & 0.5 \\
\hline Number of search agents & 5 \\
\hline Search domain & {$\left[\begin{array}{ll}0 & 1\end{array}\right]$} \\
\hline Number of runs & 10 \\
\hline \multicolumn{2}{|l|}{ CFA } \\
\hline Max number of iterations & 500 \\
\hline Swarm size & 8 \\
\hline \multicolumn{2}{|l|}{ WOA } \\
\hline Population size & 40 \\
\hline $\mathrm{B}$ & 1 \\
\hline $\mathrm{P}$ & 0.5 \\
\hline \multicolumn{2}{|l|}{ CSA } \\
\hline Number of generations & 100 \\
\hline Number of independent runs on training phase & 30 \\
\hline Number of search agents & 30 \\
\hline Issue dimension & Number of features in each data set \\
\hline
\end{tabular}


Case 1: Optimal scheduling of microgrid under grid connected mode

The performance analysis of the BIMASGO method under the grid connected mode were discussed in this section. The power analysis of generator 1, 2,3 and 4 were represented in Figure 3. Figure 3(a) signifies the generator 1 and 2 power performance. In generator 1 , the power starts $3 \mathrm{~kW}$ at $1-2$ hour, then it reduced to reach $2 \mathrm{~kW}$ at a 3-hour time. After, the power is increased to reach $5 \mathrm{~kW}$ at a 4-hour time. At the time period of 5 hours, the power is increased to reach the peak value of $6.8 \mathrm{~kW}$. Then the power is decreased to reach $1.5 \mathrm{~kW}$ at a 7 -hour time. Then the power is increased to reach $4 \mathrm{~kW}$, and then reduced to reach 3 $\mathrm{kW}$ at 9-to-10-hour time period. Again, the power is increased to reach $5 \mathrm{~kW}$, the nit reduced to $1 \mathrm{~kW}$, and then increased to reach $5 \mathrm{~kW}$. At 15 hours, the power is $4 \mathrm{~kW}$. Then the power is increased to reach $6.5 \mathrm{~kW}$. At the time duration of 18 to 21 hours the power was constant to $5 \mathrm{~kW}$. Then it reduced to reach $1.98 \mathrm{~kW}$, and then it increased to reach $4 \mathrm{~kW}$ at a 24-hour time. The generator 2 power is initially zero at the time period of 1 to 10 hours. At 11 hours, the power is increased to reach $4 \mathrm{~kW}$, and then the power is increased to reach $7.8 \mathrm{~kW}$ at a 12 -hour time. Then the power is lessened to reach $3 \mathrm{~kW}$ and it increased to reach $6.5 \mathrm{~kW}$ at a 18 -hour time. After that, the power is reduced to reach $3 \mathrm{~kW}$ at a 20-hour time. At 20 hours, it again increased to reach $5 \mathrm{~kW}$, and then it increased slightly again, it reduced to reach $2 \mathrm{~kW}$ at 24-hour time period. Figure $3(b)$ displays generator 3 and 4 power performance. Both generators 3 and 4 , the initial power become zero. At generator 3, power increased from 0 to $2 \mathrm{~kW}$ in the period of 11 hours, and then the power is increased to reach the peak value of $4.6 \mathrm{~kW}$ at 12-to-13-hour time period. Then the power is reduced to reach $3 \mathrm{~kW}$ at the 15 hours. At 16 hours, the power is increased to reach 4.4 hours, and then reduced to $2 \mathrm{~kW}$ at the time period of 18 hours. Then it increased and decreased to reach $0.8 \mathrm{~kW}$ at the period of 20 hours, then it increased to reach $2.2 \mathrm{~kW}$ at a 23-hour time. At generator 4, power increased from 0 to $3 \mathrm{~kW}$ in the period of 11 hours, and then the power is increased to reach the peak value of $4.6 \mathrm{~kW}$ at 12-to-13-hour time period. Then the power is reduced to reach $2 \mathrm{~kW}$ at the 15 hours. At 16 hours, the power is increased to reach 4.4 hours, and then reduced to $2.7 \mathrm{~kW}$ at the time period of 18 hours. Then it increased to reach around $2.9 \mathrm{~kW}$ at the period of 18 to 22 hours, then it slightly increased to reach $3.2 \mathrm{~kW}$ at the time period of 23 hours, then it suddenly reduced to zero in 23 hours. Figure 4 signifies generator 5, 6 and 7 power performances. Figure $4(a)$ represents the analys is of power in generator 5 and 6 . In the generator
5, power, value is $0.98 \mathrm{~kW}$ at 1 hour and 2-to-3-hour time the power value becomes zero. The power reaches $1 \mathrm{~kW}$ at 4 -hour time period. Then again, the power becomes zero at 5-to-7-hour time period. At 8 hours the power is again reaching to $1 \mathrm{~kW}$. After that, the power becomes zero at 9-to-17-hour time period. In 18-hour time, the power is again become $1 \mathrm{~kW}$ and it slightly decreased to reach $0.96 \mathrm{~kW}$ at 19 hours. Then the power is zero at 20-to-22-hour time period. At 23 to 24 hours the power value is under $1 \mathrm{~kW}$. In the generator 6, power, value is $0.97 \mathrm{~kW}$ at 2-to-4-hour time and 4 to 6 hours the power value becomes zero. In 6-hour time period, the power is increased from 0 to $0.98 \mathrm{~kW}$. Then again, the power becomes zero at 7hour time period. At 8 hours the power is again increased from 0 to $1 \mathrm{~kW}$. After that, the power becomes zero at 9-to-18-hour time period. In 19-hour time period, the power is again increased from 0 to $0.97 \mathrm{~kW}$ and it decreased to 0 . Then the power is increased from zero to $1 \mathrm{~kW}$ at 21-to-22-hour period. At 23 to 24 hours the power value is zero. Then the power is increased to reach $0.9 \mathrm{~kW}$ at a 24 -hour time. Figure $4(b)$ displays the generator power analysis. In generator 7 , the power initiates $5 \mathrm{~kW}$ at 1 hour time period, and then the power is reduced to reach $3.9 \mathrm{~kW}$ at 2-hour time period. Again, the power is increased to reach $4 \mathrm{~kW}$ and reduced to reach $3 \mathrm{~kW}$ at a 4-hour time. At 5 hours, the power reaches to $8.7 \mathrm{~kW}$ then it reduced to reach $1.9 \mathrm{~kW}$ at 6 hours. Then the power is increased to reach $8.2 \mathrm{~kW}$ and then it reduced to reach $5 \mathrm{~kW}$ at 8 hours. The power value becomes $10 \mathrm{~kW}$ at 9-to-10-hour time period. The power becomes zero from 11 to 18 hours. At 19 hours the power becomes $1 \mathrm{~kW}$. Then again, it becomes zero at 20 to 24 hours.

Figure 5 shows the cost comparison of BIMASGO with existing approaches. Figure $5(a)$ displays the cost comparis on of dragonfly algorithm and proposed approach. The proposed approach cost is below $60 \$$ and the DFA approach cost is $100 \$$ at 0 to $1 \mathrm{~h}$ time period. Then, the cost is increased to reach $150 \$$ at $4 \mathrm{~h}$ in DFA approach and $90 \$$ at the time period of $4 \mathrm{~h}$ in the proposed approach. After that, the cost of DFA is $130 \$$ at 5 to $9 \mathrm{~h}$ time. But, in the proposed approach, cost is $70 \$$ at 5 to $7 \mathrm{~h}$ and again, it decreased to reach $50 \$$ at 7 to $8 \mathrm{~h}$ time, again it increased to reach $80 \$$ at 8 to $10 \mathrm{~h}$. In DFA approach cost is $100 \$$ at the $10 \mathrm{~h}$ time. The cost of DFA is gradually increased from 100 $\$$ to $620 \$$ at 10 to $13 \mathrm{~h}$ time, at the same time the cost of BIMASGO method also increased from 50 to 550 $\$$. Then the cost of BIMASGO method is increased slightly i.e $560 \$$ at the time period of 14 hours. The DFA approach is decreased to reach $520 \$$ at the time of 14 to $15 \mathrm{~h}$. From 15 to $18 \mathrm{~h}$ time, the DFA approach 
has gradually increased from 520 to $720 \$$ and the proposed approach has increased from 480 to $690 \$$. Then the DFA approach cost is decreased to reach 640 $\$$ and the proposed approach cost is also decreased to reach $580 \$$ at $19 \mathrm{~h}$. At $20 \mathrm{~h}$, the proposed and DFA cost increases as the value of $605 \$ 660 \$$ respectively. Then the cost of proposed and DFA is decreased to reach $550 \$, 590 \$$ at $21 \mathrm{~h}$. Again, the cost of proposed and DFA is decreased to reach $280 \$, 300 \$$ at the time period of 23 to $24 \mathrm{~h}$ respectively. From the Figure 5(a), it is clearly depicting the proposed approach cost is minimal likened to the DFA approach. Figure $5(b)$ shows the cost comparison of firefly and BIMASGO method. At 0 to $10 \mathrm{~h}$, the FF approach cost is constant to $170 \$$. But the BIMASGO approach cost is varying that is the BIMASGO approach cost is $60 \$$ at 0 to $1 \mathrm{~h}$ time period. Then, the cost is increased to reach $90 \$$ at the time period of $4 \mathrm{~h}$ in the proposed approach. After that, the cost is $70 \$$ at 5 to $7 \mathrm{~h}$ and again, it decreased to reach $50 \$$ at 7 to $8 \mathrm{~h}$ time, again it increased to reach $80 \$$ at 8 to $10 \mathrm{~h}$. In 11 to $13 \mathrm{~h}, \mathrm{FF}$ approach cost is gradually increased to reach 620 \$. At the same time proposed approach cost is also increased to reach $510 \$$. The FF approach and proposed approach are decreased to reach $550 \$, 480 \$$ at the time of $15 \mathrm{~h}$. From 15 to $18 \mathrm{~h}$ time, the proposed approach has gradually increased from 480 to $590 \$$ and the FF approach is increased from 550 to $750 \$$. Then the FF approach cost is decreased to reach $640 \$$ and the proposed approach cost is also decreased to reach $580 \$$ at $19 \mathrm{~h}$. At $20 \mathrm{~h}$, the proposed and FF cost increases as the value of $505 \$, 680 \$$ respectively. Then the cost of proposed and FF approach is decreased to reach $550 \$, 590 \$$ at $22 \mathrm{~h}$. Again, the cost of proposed and FFA is decreased to reach $280 \$, 310 \$$ at the time period of 23 to $24 \mathrm{~h}$ respectively. The proposed approach cost is lower than the FFapproach is clearly depicted the Figure $5(b)$. Figure $6(a)$ depicts the cost comparison of gravitational search algorithm with the proposed approach. At 0 to $10 \mathrm{~h}$, the GSA approach cost is constant to $180 \$$. But the BIMASGO approach cost is varying that is the BIMASGO approach cost is $60 \$$ at 0 to $1 \mathrm{~h}$ time period. Then, the cost is increased to reach $90 \$$ at the time period of $4 \mathrm{~h}$ in the proposed approach. After that, the cost is $70 \$$ at 5 to $7 \mathrm{~h}$ and again, it decreased to reach $50 \$$ at 7 to $8 \mathrm{~h}$ time, again it increased to reach $80 \$$ at 8 to $10 \mathrm{~h}$. In 11 to $13 \mathrm{~h}$, GSA approach cost is gradually increased to reach $650 \$$. At the same time proposed approach cost is also increased to reach 520 $\$$. The GSA approach and proposed approach are decreased to reach $500 \$, 470 \$$ at the time of $15 \mathrm{~h}$. From 15 to $18 \mathrm{~h}$ time, the proposed approach has gradually increased from 470 to 690 \$ and the GSA approach is increased from 500 to 760 \$. Then the GSA approach cost is gradually decreased to reach $610 \$$ at the time period of $22 \mathrm{~h}$ and the proposed approach cost is also decreased to reach $570 \$$ at $19 \mathrm{~h}$. At $20 \mathrm{~h}$, the proposed cost increases as the value of $600 \$$ respectively. Then the cost of the proposed approach is decreased to reach $550 \$$ at $22 \mathrm{~h}$. Again, the cost of proposed and GSA is decreased to reach $280 \$$, $310 \$$ at 23 to $24 \mathrm{~h}$ time.

Figure 6(b) displays cost comparison of proposed and modified dragonfly with the whale optimization algorithm. The proposed approach cost is $60 \$$ and the MDAWO approach cost is $80 \$$ at 0 to $1 \mathrm{~h}$ time period. Then, the cost is increased to reach $100 \$$ at 3 to $4 \mathrm{~h}$ in MDAWO approach and $90 \$$ at the time period of 2 to $4 \mathrm{~h}$ in the proposed approach. After that, the cost of MDAWO is increased to reach $130 \$$ at the $4 \mathrm{~h}$ time. But, in the proposed approach, cost is $110 \$$ at $4 \mathrm{~h}$ and again, it decreased to reach $80 \$$ at 5 to $8 \mathrm{~h}$ time, again it decreased to reach $60 \$$ at 7 to $8 \mathrm{~h}$. In MDAWO approach cost is $100 \$$ at 8 to $9 \mathrm{~h}$ time. The cost of MDAWO is gradually increased from $80 \$$ to $560 \$$ at 10 to $13 \mathrm{~h}$ time, at the same time the cost of BIMASGO model also increased from 50 to $550 \$$. Then the cost of BIMASGO approach is increased slightly i.e., 560 $\$$ at the time period of 14 hours. The MDAWO approach is decreased to reach $500 \$$ at the time of $15 \mathrm{~h}$. From 15 to $18 \mathrm{~h}$ time period, MDAWO approach has gradually increased from 500 to $705 \$$ and the proposed approach is increased from 480 to $690 \$$. Then the MDAWO approach cost is decreased to reach $600 \$$ and the proposed approach cost is also decreased to reach $580 \$$ at $19 \mathrm{~h}$. At $20 \mathrm{~h}$, the proposed and MDAWO cost increases as the value of $605 \$$, $630 \$$ respectively. Then the cost of proposed and MDAWO are decreased to reach $550 \$, 590 \$$ at 21 to $22 \mathrm{~h}$. Again, the cost of proposed and MDAWO is decreased to reach $280 \$, 285 \$$ at the time period of 23 to $24 \mathrm{~h}$ respectively. Figure $6(\mathrm{c})$ shows that the cost comparison of proposed and cuttlefish with crow search optimization approach. The proposed approach cost is $60 \$$ and the Cuttlefish and Crow Search (CFCS) approach cost is $80 \$$ at 0 to $1 \mathrm{~h}$ time period. Then, the cost is increased to reach $100 \$$ at 3 to $4 \mathrm{~h}$ in CFCS approach and $90 \$$ at the time period of 2 to $4 \mathrm{~h}$ in the proposed approach. After that, the cost of CFCS is increased to reach $120 \$$ at $4 \mathrm{~h}$ time period. But, in the proposed approach, cost is $105 \$$ at $4 \mathrm{~h}$ and again, it decreased to reach $80 \$$ at 5 to $8 \mathrm{~h}$ time period, again it decreased to reach $60 \$$ at 7 to $8 \mathrm{~h}$. In CFCS approach cost is $90 \$$ at 8 to $9 \mathrm{~h}$ time. The cost of CFCS is gradually increased from $80 \$$ to $560 \$$ at 10 to $13 \mathrm{~h}$ time, at the same time the cost of BIMASGO method 
also increased from 50 to $550 \$$. Then the cost of BIMASGO method is increased slightly i.e., $560 \$$ at the time period of 14 hours. The CFCS approach is decreased to reach $500 \$$ at the time of $15 \mathrm{~h}$. From 15 to $18 \mathrm{~h}$ time, CFCS approach has gradually increased from 500 to $700 \$$ and the proposed approach has increased from 480 to 690 \$. Then the CFCS approach cost is decreased to reach $600 \$$ and the proposed approach cost is also decreased to reach $580 \$$ at $19 \mathrm{~h}$. At $20 \mathrm{~h}$, the proposed and CFCS cost increases as the value of $605 \$, 620 \$$ respectively. Then the cost of proposed and CFCS are decreased to reach 550\$, 560 $\$$ at 21 to $22 \mathrm{~h}$. Again, the cost of proposed and CFCS is decreased to reach $280 \$, 283 \$$ at the time period of 23 to $24 \mathrm{~h}$ respectively. From the Figure 5 and 6 , it is clearly depicted, the proposed approach is less cost compared to other existing approaches. Here, the BIMASGO approach under the islanded mode analysis. The power analysis of generator 1 and 2, 3 and 4, 5 and 6 is shown in Figure 7.

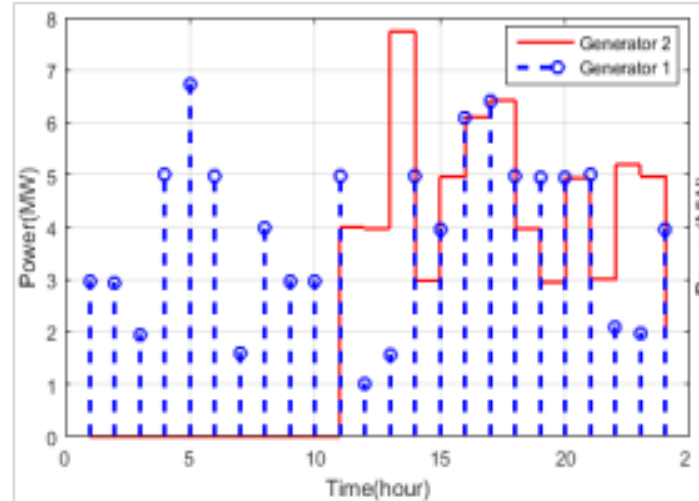

(a)

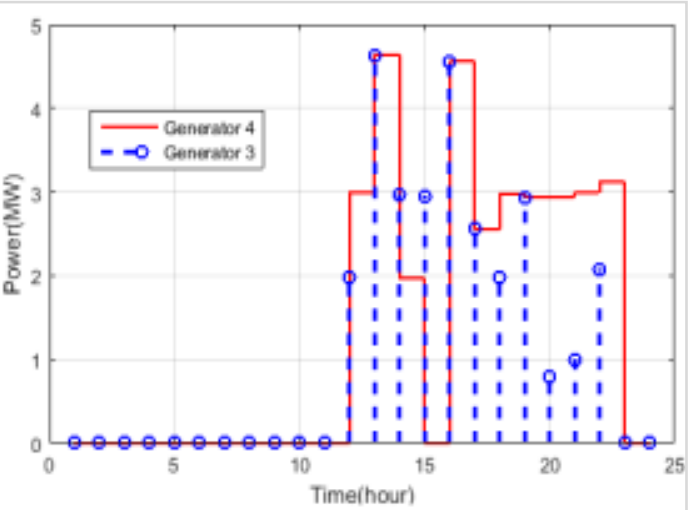

(b)

Figure 3 Power performance of (a) Generator 1, 2 (b) Generator 3, 4

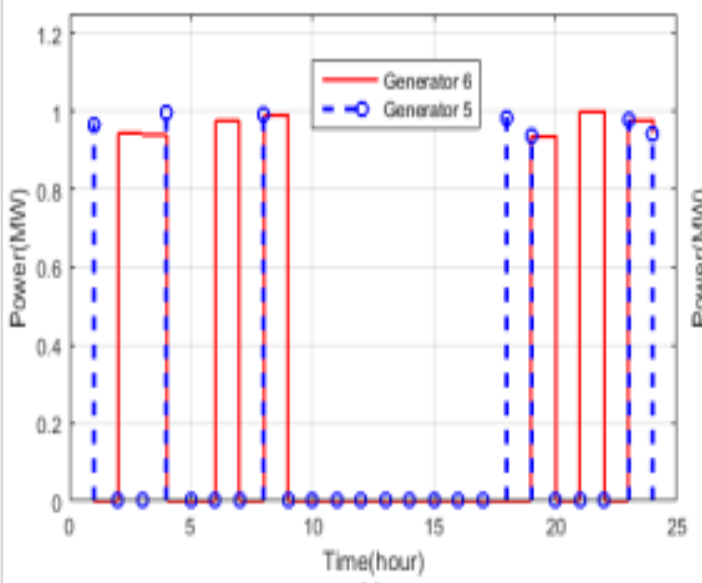

(a)

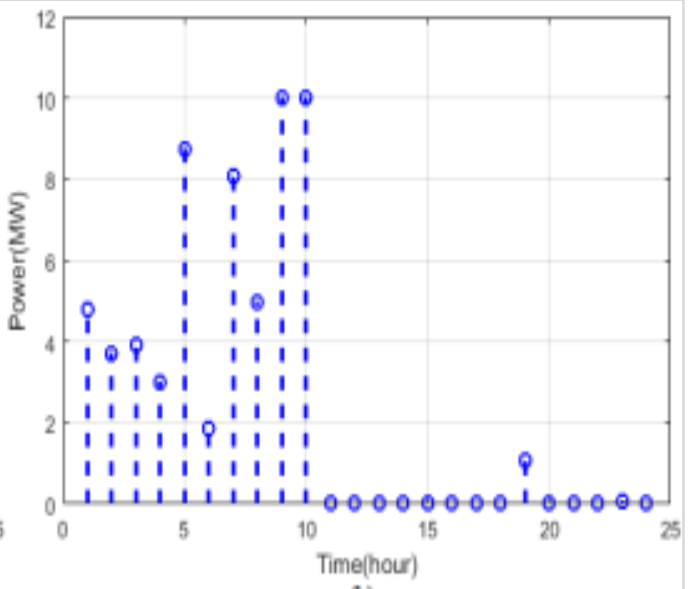

(b)

Figure 4 Power performance of (a) Generator 5, 6 (b) Generator 7 

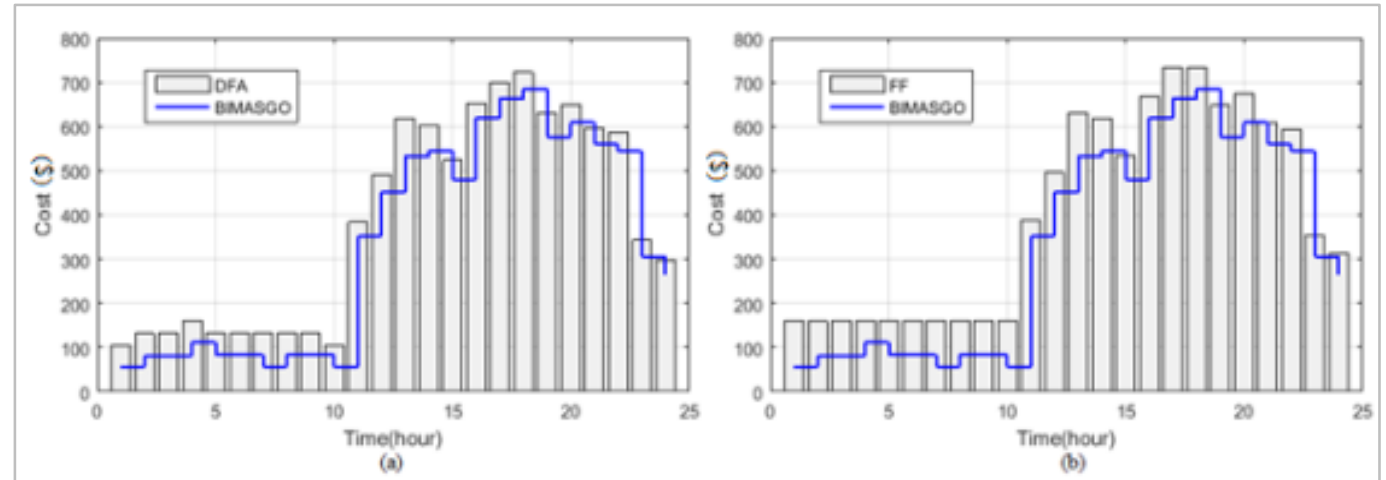

Figure 5 Cost Comparison of (a) DFA with proposed approach (b) FF with proposed approach

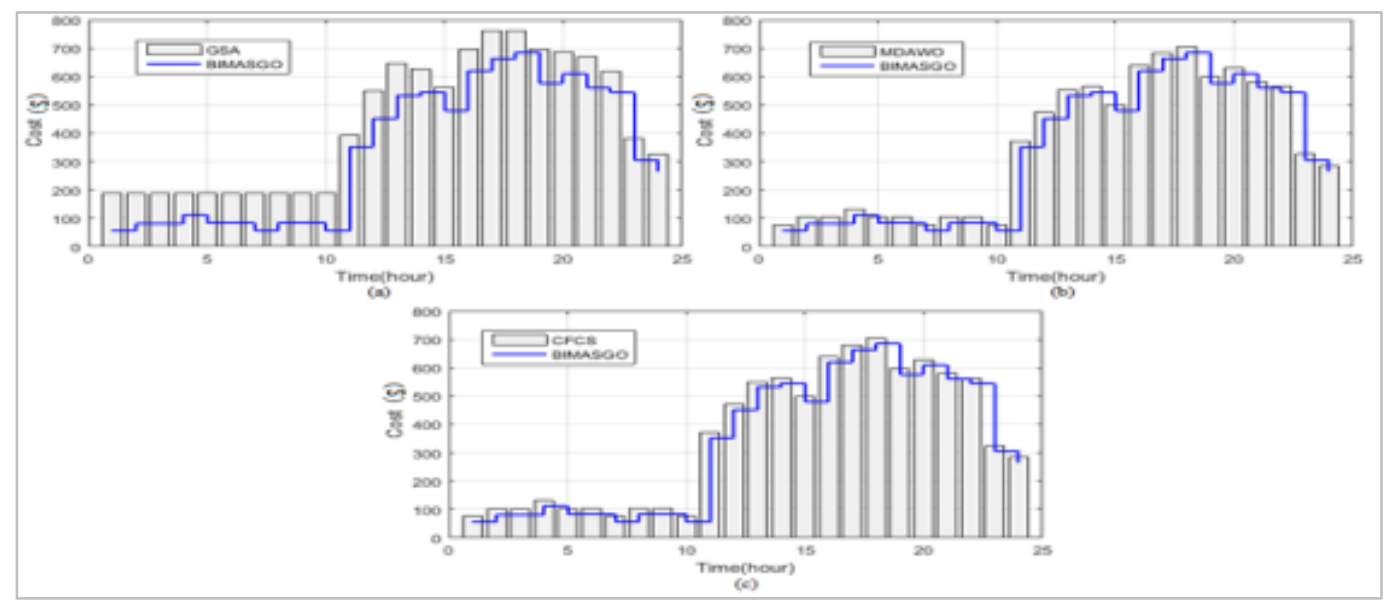

Figure 6 Cost comparison of (a) GSA with proposed approach (b) Modified Dragonfly Algorithm and Whale Optimization (MDAWO) with proposed approach (c) CFCS with proposed approach

Case 2: Optimal scheduling of microgrid under islanded mode

Figure $7(a)$ depicts the power analysis of generator 1 and 2 . The power of generator 1 is initially zero at the time period of 1 to 10 hours. At 11 hours, the power is increased to reach $5 \mathrm{~kW}$, and then the power is decreased to reach $3 \mathrm{~kW}$ at 12 -hour time period. Then the power is increased to reach $5 \mathrm{~kW}$ and it decreased to reach $3.8 \mathrm{~kW}$ at 15 -hour time intervals. After that, power is reduced to reach $3 \mathrm{~kW}$ at 20 -hour time period. At 19 hours, it again increased to reach $7.4 \mathrm{~kW}$, then it decreased again, it reduced to reach $3 \mathrm{~kW}$ at 23 -hour time period. Then the power is increased to reach 4.5 $\mathrm{kW}$ at 24-hour time period. The Generator 2 power starts at $4 \mathrm{~kW}$ at 1 hour, and then it reduced to reach 2 $\mathrm{kW}$ at 2-hour time period. The power is increased to reach $4 \mathrm{~kW}$ at 3-hour time period. In 5-hour time, the power is increased to reach the value of $3 \mathrm{~kW}$. Then the power is decreased to reach $2 \mathrm{~kW}$ at 8 -hour time period. Then the power is increased to reach $3.5 \mathrm{~kW}$, and then reduced to reach $3.2 \mathrm{~kW}$ at 9-to-10-hour time period. Again, the power is increased to reach $5 \mathrm{~kW}$, then it increased to $6.2 \mathrm{~kW}$, and then reduced to reach $4 \mathrm{~kW}$. At 15 -hour, 17 hours and 19 hours the power is $4 \mathrm{~kW}$. Then the power is increased to reach $7.5 \mathrm{~kW}$ at 20 hour time period. Then it reduced to reach $4 \mathrm{~kW}$, and then it increased to reach peak values of $7.6 \mathrm{~kW}$ at 23-hour time period. Then the power is diminished to reach $4 \mathrm{~kW}$.

Figure $7(b)$ depicts the power analysis of generator 3 and 4 . At 0 to $11 \mathrm{~h}$, both generators 3 and 4 , the power become zero. At $12 \mathrm{~h}$, the generator 3 and 4 power are increased from 0 to $6.2 \mathrm{~kW}$, and then the power is reduced to reach $2 \mathrm{~kW}$ at 13 -hour time period. Then, the power of generator 3 is reduced to reach $0.8 \mathrm{~kW}$ at 14 hours and at the same time generator for power is 2 $\mathrm{kW}$. Then the power of generator 3 and 4 are increased to reach $3 \mathrm{~kW}, 2.2 \mathrm{~kW}$ at $15 \mathrm{~h}$ respectively. At 16 hours, the generator 3 , power is decreased to reach $1.5 \mathrm{~kW}$ and the generator 4 , power is decreased to zero in 15 to $16 \mathrm{~h}$ and then increased to $2 \mathrm{~kW}$ at 16 -hour time period. At $17 \mathrm{~h}$, the generator 3 and 4 power are increased to reach $3 \mathrm{~kW}$, and then the power is slightly 
decreased to reach $2.8 \mathrm{~kW}$ for both generators at $18^{\text {th }}$ $\mathrm{h}$. The power of generator 3 is decreased to reach $2 \mathrm{~kW}$ and generator 4 is decreased to reach $2.8 \mathrm{~kW}$ at the time period of $19 \mathrm{~h}$. At $20 \mathrm{~h}$, the generator 3 and 4 power are increased to reach $5.5 \mathrm{~kW}$. At $21 \mathrm{~h}$, the generator 3 and 4 power are decreased to reach $3 \mathrm{~kW}$. At $22 \mathrm{~h}$, the generator 3 and 4 power are decreased to reach $2 \mathrm{~kW}, 0.8 \mathrm{~kW}$. At 23 to $24 \mathrm{~h}$, the power of generating 3 becomes zero and the generator 4 , at $23 \mathrm{~h}$ is reduced from $0.8 \mathrm{~kW}$ to 0 and $24 \mathrm{~h}$, generator 4 power become zero.

Figure $7(c)$ shows the analys is of power in generator 5 and 6 . In the generator 5 and 6 , power, value was $0.98 \mathrm{~kW}$ at the time period of 1 hour. At $3 \mathrm{~h}$, the generator 5 and 6 , power becomes $0,0.9 \mathrm{~kW}$. At $2 \mathrm{~h}$, the generator 5 and 6 , power becomes $0,0.9 \mathrm{~kW}$. The generators 5 and 6 , the generated power is 0 and 0.9 $\mathrm{kW}$ at the time period of $4 \mathrm{~h}$. At 5 to $7 \mathrm{~h}$, the generator 6 power becomes zero. The generator 5 power is around $0.98 \mathrm{~kW}$ at 5 to $9 \mathrm{~h}$ time and the generator power become zero at 10h. At $8 \mathrm{~h}$, the generator 6 power is $1 \mathrm{~kW}$ and it became zero at the time period of 9 to $10 \mathrm{~h}$. At $11 \mathrm{~h}$, the generator 5 and 6 power becomes $1 \mathrm{~kW}$. At 12 to $14 \mathrm{~h}$, the generator 6 power becomes zero. The generator 5 power is $0.98 \mathrm{~kW}$ at $12 \mathrm{~h}$ and it reduced to zero, then it increased to $0.98 \mathrm{~kW}$ at $14 \mathrm{~h}$. At $15 \mathrm{~h}$, the power of generator 5 and 6 are $0.9 \mathrm{~kW}$, then the power is decreased to reach zero for generator 6 and the generator 5 also reduced from 0.9 to 0 at $16 \mathrm{~h}$. At $17 \mathrm{~h}$, the power is increased to $1 \mathrm{~kW}$ at both generators 6 and 5 . At $18 \mathrm{~h}$, the power is again zero at generator 6 and the generator 5 , power is reduced from $1 \mathrm{~kW}$ to zero. At $19 \mathrm{~h}$ the power of generator 5 and 6 becomes $0.8 \mathrm{~kW}$. Then the power of generating 6 becomes zero at 20 to $24 \mathrm{~h}$ time. The generator 5 , power becomes diminished to zero at $20 \mathrm{~h}$ to $24 \mathrm{~h}$ and at $24 \mathrm{~h}$ it increased to reach $0.9 \mathrm{~kW}$. Figure 8 displays the cost comparison of proposed with existing approaches.

Figure 8 (a) specifies the cost comparison of dragonfly algorithm with the proposed approach. The proposed approach cost is below $100 \$$ at 0 to $11 \mathrm{~h}$ time period and the DFA cost is below $100 \$$ at 1 to 2 $\mathrm{h}$ and $130 \$$ at $3 \mathrm{~h}$, again $100 \$$ at 4 to $8 \mathrm{~h}$ period. The proposed approach cost is increased from $320 \$$ to 550 $\$$ at 11 to $14 \mathrm{~h}$ time and at the same time DFA cost is increased to reach $600 \$$. At 15 hours the cost is increased to reach $520 \$, 550 \$$, in the proposed approach and DFA approach. The cost of DFA approach is again increased to reach above $600 \$$ at the time period of 16 to 18 hours. Then the cost is reduced to reach $580 \$$ at 19 -hour time period and the proposed approach reach 550 \$. Again, the cost is slightly increased then decreased to reach 550 \$ in the DFA approach. Then the cost is gradually reduced to reach $300 \$$ at 24 -hour time period. At 24 hours it reduced to reach $280 \$$. From the figure it is clearly known that the proposed approach cost is smaller than the existing approach.

Figure $8(b)$ displays the cost comparis on of firefly and BIMASGO method. The cost of the proposed approach is $60 \$$ at 0 to $7 \mathrm{~h}$ time, simultaneously the FF cost is above $110 \$$. At $8 \mathrm{~h}$, the cost of BIMASGO approach attains $80 \$$, cost of FF attains $160 \$$. Then the cost is reduced to reach $100 \$$ and the proposed approach cost is 60 \$at 9 hours. Then the cost is slightly increased to reach the value of $150 \$$ in FF and $80 \$$ in the proposed approach at the time period of 10 hours. At 11 to 14 hours, the cost of the FF and proposed approach are increased to reach the value of $630 \$, 550 \$$ respectively. Then the cost is decreased to reach $550 \$$ in FF approach, $530 \$$ in the proposed approach at the $15 \mathrm{~h}$ time. Then, BIMASGO and FF methods, cost is increased to reach $610 \$, 690 \$$ at the $16 \mathrm{~h}$ time. Then the cost value is decreased to reach $660 \$$ for FF approach, $600 \$$ for the proposed approach. After that, the cost value is decreased to reach 580 \$ for FF approach, $540 \$$ for a proposed approach at the $19 \mathrm{~h}$ time. Again, the cost is increased to reach 650 \$for FF approach, $600 \$$ for a proposed approach at the $20 \mathrm{~h}$ time. After that, the cost value is decreased to reach $590 \$$ for FF approach, $530 \$$ for a proposed approach at 21 to $22 \mathrm{~h}$ time. Again, cost value is decreased to reach $310 \$$ for FF approach, 250 $\$$ for a proposed approach at 24 to $25 \mathrm{~h}$ time. It also clearly depicts that the BIMASGO method cost is low compared to the firefly cost system. Figure 9 depicts that cost comparison of BIMASGO and existing approaches. Figure 9 (a) depicts that cost comparison of gravitational search algorithm with BIMASGO method. The proposed approach cost is below $100 \$$ at 0 -to-11-hour period. The cost is increased to reach 320 $\$$ at 11 -hour period and the cost reaches $450 \$$ at $12-$ hour time period. The cost is again increased to reach $540 \$$ at the time period of 13 hours, then it again slightly increased to reach $500 \$$. At 15 hours the cost is increased to reach $550 \$$. The cost is again increased to reach above $600 \$$ at the time period of 16 to 18 hours. Then the cost is reduced to reach $580 \$$ at 19 hour time period. Again, the cost is slightly increased then decreased to reach $550 \$$. Then the cost is gradually reduced to reach $300 \$$ at 24 -hour time period. At 24 hours it reduced to reach $280 \$$. In the GSA approach, the cost value is start at above $100 \$$ at 0 to $10 \mathrm{~h}$ time. Compared to proposed system this cost 
value is two times larger. Then the cost value is increased to reach above $600 \$$ at 10 to $14 \mathrm{~h}$ time. At 15 hours, the cost value of GSA and the proposed approach is same that is around $550 \$$. At $16-17 \mathrm{~h}$, the cost of GSA is again raised to reach $690 \$$, at the same time the proposed approach $620 \$$. At $18 \mathrm{~h}$, the cost of GSA is raised to reach high value i.e., $750 \$$ but the peak range of proposed approach is $620 \$$ only. Then the cost is decreased to reach $690 \$$ at 19 to $20 \mathrm{~h}$ time. Then the cost is reduced to reach $600 \$$ at 21 to $22 \mathrm{~h}$ time. After that, the cost is decreased to reach $350 \$$ at 23 to $24 \mathrm{~h}$ time period. Compared to 0 to $24 \mathrm{~h}$ cost value, the proposed system is less cost value than the existing GSA approach.

Figure 9 (b) depicts the cost comparison of BIMASGO and modified dragonfly along whale optimization algorithm. The cost of BIMASGO approach is $60 \$$ at 0 to $7 \mathrm{~h}$ time, simultaneously the MDAWO cost is $75 \$$. At $8 \mathrm{~h}$, the cost of BIMASGO approach attains $80 \$$, the cost of MDAWO attains 100 $\$$. Then the cost is reduced to reach $80 \$$ and the proposed approach cost is $60 \$$ at 9 hours. Then the cost is slightly increased to reach the value of $110 \$$ in MDAWO and $80 \$$ in the proposed approach at the time period of 10 hours. At 11 to 14 hours, the cost of the MDAWO and proposed approach is increased to reach the value of $590 \$, 550 \$$ respectively. Then the cost is decreased to reach $540 \$$ in MDAWO approach, $530 \$$ in the proposed approach at the $15 \mathrm{~h}$ time. Then, the BIMASGO and MDAWO method cost is increased to reach $650 \$, 610 \$$ at the $16 \mathrm{~h}$ time. Then the cost value is decreased to reach $610 \$$ for MDAWO approach, $600 \$$ for the proposed approach. Then the cost value is increased to reach $650 \$$ for MDAWO approach, $50 \$$ for a proposed approach at $18 \mathrm{~h}$ time period. After that, cost value is decreased to reach 550 $\$$ for MDAWO approach, 540 \$ for a proposed approach at $19 \mathrm{~h}$ time interval. Again, the cost is increased to reach 610 \$for MDAWO approach, 600 \$ for a proposed approach at $20 \mathrm{~h}$ time period. After that, cost value is decreased to reach $540 \$$ for MDAWO approach, $530 \$$ for a proposed approach at 21 to 22 time period. Again, cost value is decreased to reach $270 \$$ for MDAWO approach, 250 \$ for a proposed approach at 24-to-25-time interval.

Figure 9 (c) indicates that cost comparison of proposed and cuttlefish with crow search optimization approach. The cost of BIMASGO approach is $60 \$$ at 0 to $7 \mathrm{~h}$ time, simultaneously the CFCS cost is $70 \$$. At $8 \mathrm{~h}$, the cost of BIMASGO approach attains $80 \$$, the CFCS cost attains $100 \$$. Then the cost is reduced to reach $80 \$$ and the proposed approach cost is $60 \$ a t$
9 hours. Then the cost is slightly increased to reach the value of $110 \$$ in CFCS and $80 \$$ in the proposed approach at the time period of 10 hours. At 11 to 14 hours, the cost of the CFCS and proposed approach are increased to reach the value of $590 \$ 550 \$$ respectively. Then the cost is decreased to reach $540 \$$ in CFCS approach, $530 \$$ in the proposed approach at the $15 \mathrm{~h}$ time. Then, the BIMASGO and CFCS method cost is increased to reach $610 \$, 650 \$$ at the $16 \mathrm{~h}$ time. Then the cost value is decreased to reach $610 \$$ for CFCS approach, $600 \$$ for the proposed approach. Then the cost value is increased to reach $650 \$$ for CFCS approach, $50 \$$ for a proposed approach at $18 \mathrm{~h}$ time period. After that, cost value is decreased to reach $550 \$$ for CFCS approach, $540 \$$ for a proposed approach at the $19 \mathrm{~h}$ time. Again, the cost is increased to reach 610 ffor CFCS approach, $600 \$$ for a proposed approach at the $20 \mathrm{~h}$ time. After that, the cost value is decreased to reach $540 \$$ for CFCS approach, $530 \$$ for a proposed approach at 21 to $22 \mathrm{~h}$ time. Again, the cost value is decreased to reach $270 \$$ for CFCS approach, $250 \$$ for a proposed approach at 24 to $25 \mathrm{~h}$ time. From the above Figure 9, it is clearly depicted, the proposed method attains lesser cost compared to other existing methods.

Figure 10 shows the percentage of energy generated in the microgrid under islanding mode operation for a 12-hour time period than $20 \%$ of the power is generated by the generator 1 and $25 \%$ of the power is generated by the generator 2 . At 12 hours the generator 3 generates $25.3 \%$ power and the generator 4 is generating $25.3 \%$ power than $3.673 \%$ of the power is generated by the generator 5 and the generator 6 not generates any power. Figure 11 shows the percentage of energy generated in the microgrid under islanding mode operation at the time period of $15^{\text {th }}$ hour. $29 \%$ of the power is generated by the generator 1 and $29 \%$ of the power is generated by the generator 2 . At 15 hours the generator 3 generates $17.48 \%$ power and the generator 4 generates $12.82 \%$ power. $5.71 \%$ of the power is generated by the generator 5 and the generator 6. Figure 12 shows the computation time comparis on of proposed and existing approaches. The proposed approach computation time is less around 5 sec. The existing approaches like DFA, FF, GSA, MDAWO, CFCS computing time is 20,18,15,12,10 seconds. Compared to the existing approaches proposed approach computing time is very less.

Table 1 illustrates the characteristic of dispatchable and non-dis patchable generator and its capacity and up and down rate. The generator 1 , the cost coefficient is $27.70 \$ / \mathrm{MWh}$. The minimum to maximum capacity is 
1.0-5.0MW. The minimum up or down time is 3 hours. Ramp up/ down rate become $2.50 \mathrm{MW} / \mathrm{h}$. In generator 2 , the cost coefficient is $39.10 \$ / \mathrm{MWh}$. The minimum to maximum capacity is $1.0-5.0 \mathrm{MW}$. The minimal up or down time is 3 hours. Ramp up/ down rate becomes $2.50 \mathrm{MW} / \mathrm{h}$. In generator 3 , the cost coefficient is $61.30 \mathrm{\$} / \mathrm{MWh}$. The minimum to maximum capacity is $0.8-3.0 \mathrm{MW}$. The minimum up or down time is 1 hour. Ramp up/ down rate become 3.0 MW/h. In generator 4 , the cost coefficient is 65.60 $\$ / \mathrm{MWh}$. The minimum to maximum capacity is 0.8 3.0 MW. The minimal up or down time is 1 hour. Ramp up/ down rate become $3.0 \mathrm{MW} / \mathrm{h}$. In generator 5 , the cost coefficient is $0 \$ / \mathrm{MWh}$. The minimum to maximum capacity is $0-1.0 \mathrm{MW}$. In generator 6 , the cost coefficient is $0 \$ / \mathrm{MWh}$. The minimum to maximum capacity is $0-1$. 5MW.Table 2 illustrated the characteristics of adjustable load under the islanded condition. Here, the capacity of adjustable loads like TV, water heater, air conditioner, fridge is presented in here, which are represented as L1, L2, L3, L4. The required energy of adjustable loads and its start and end time and the up time also illustrated. Table 2 and Table 3, data set is used to process the proposed method. Based on the load requirement, the microgrid is scheduling. Scheduling of adjustable load for grid connected mode is described in Table 4. LI load scheduled at the time of 1 to 5 hours and the L2 load is scheduled at the time of 1 to 5 hours. The L3 load is scheduled at the time of 1 to 3 hours and the L4 load is scheduled at the time of 1 to 8 hours. Scheduling of adjustable load for islanded mode is described in Table 5. In the islanded mode LI load scheduled at the time of 11 to 55 hours and the L2 load is scheduled at the time of 15 to 19 hours. The L3 load is scheduled at the time of 16 to 18 hours and the L4 load is scheduled at the time of 14 to 22 hours. Table 6 tabulates modeling metrics established to the previous method under the count of 50 and 100 trial. Efficiency under various numbers of trails is depicted in Table 7. Complete list of abbreviations is shown in Appendix I.

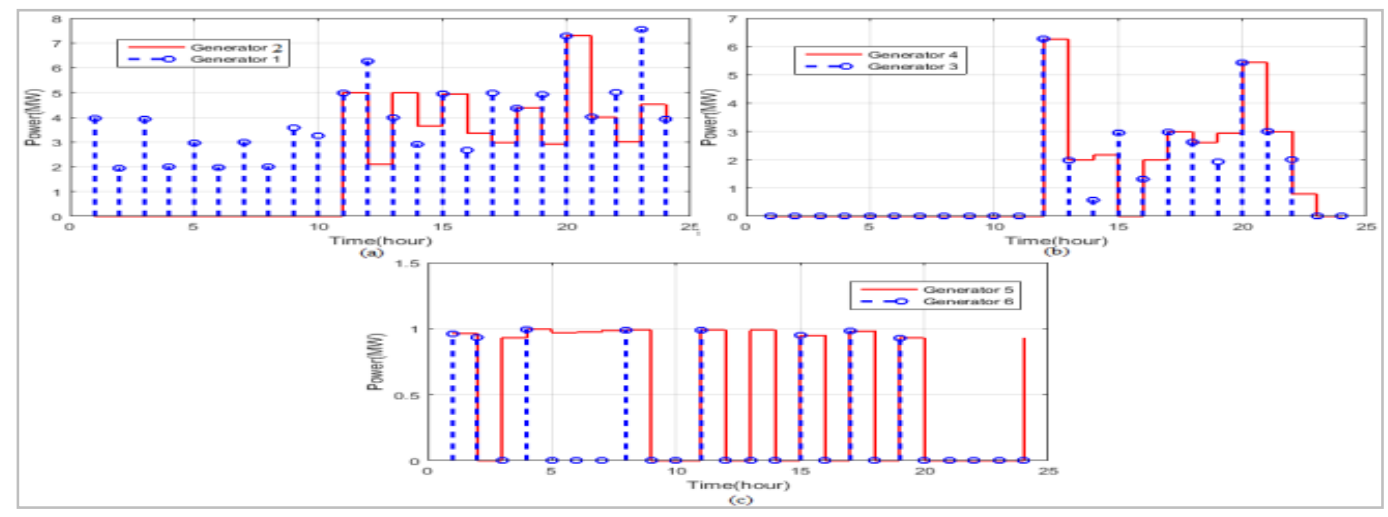

Figure 7 Analysis of power in (a) Generator 1, 2 (b) Generator 3, 4 (c) Generator 5, 6

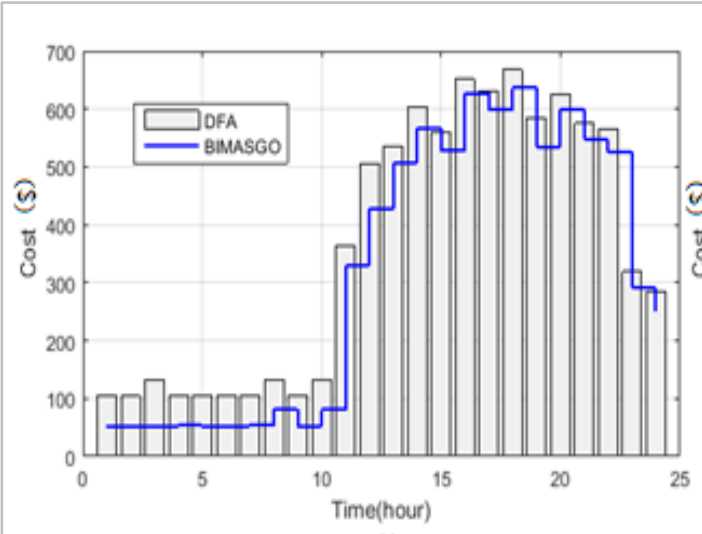

(a)

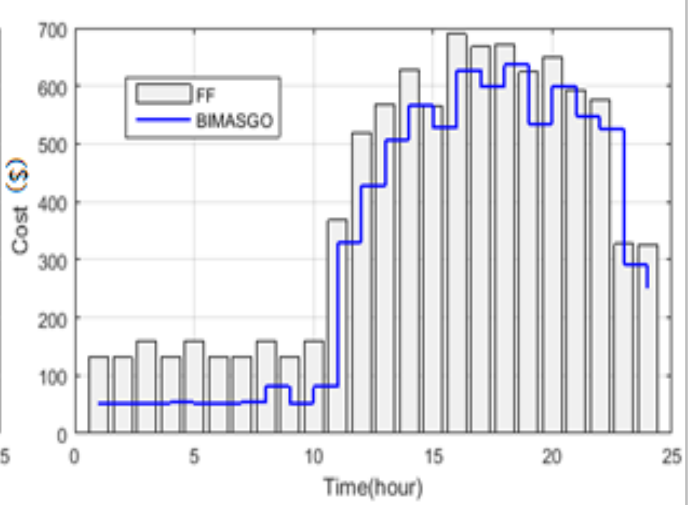

(b)

Figure 8 Cost Comparis on of (a) DFA with proposed approach (b) FF with proposed approach 
International Journal of Advanced Technology and Engineering Exploration, Vol 8(80)

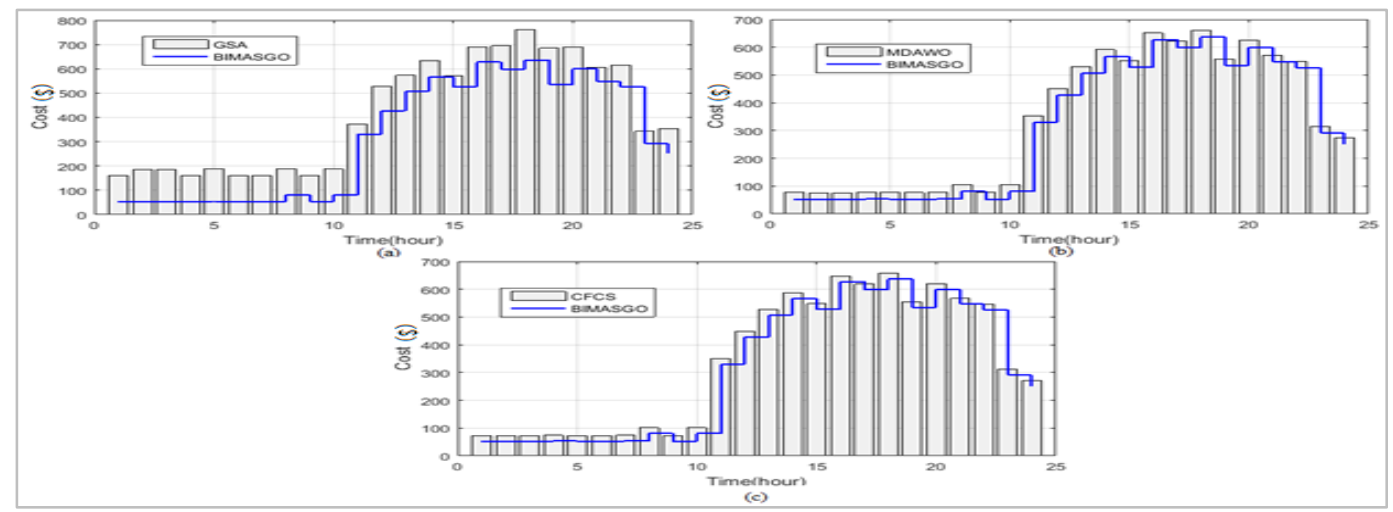

Figure 9 Cost comparis on of (a) GSA with proposed approach (b) MDAWO with proposed approach (c) CFCS with proposed approach

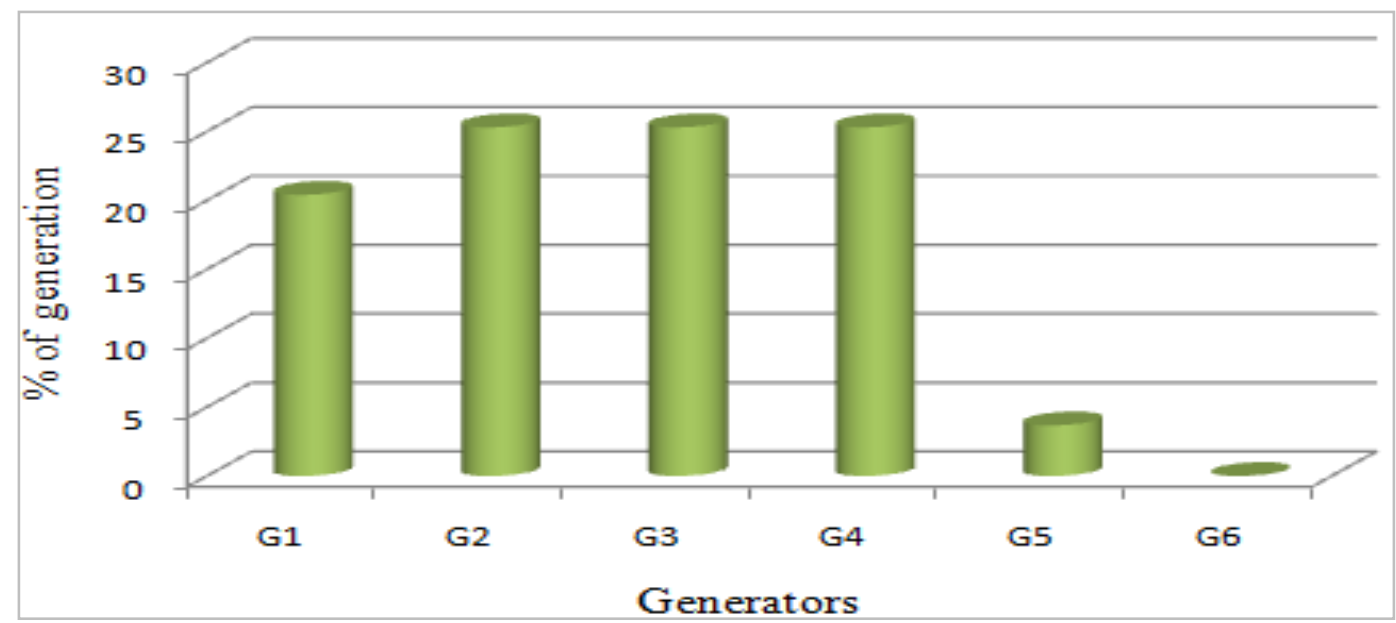

Figure 10 Percentage of energy generated in the microgrid under islanding mode operation (12th hour)

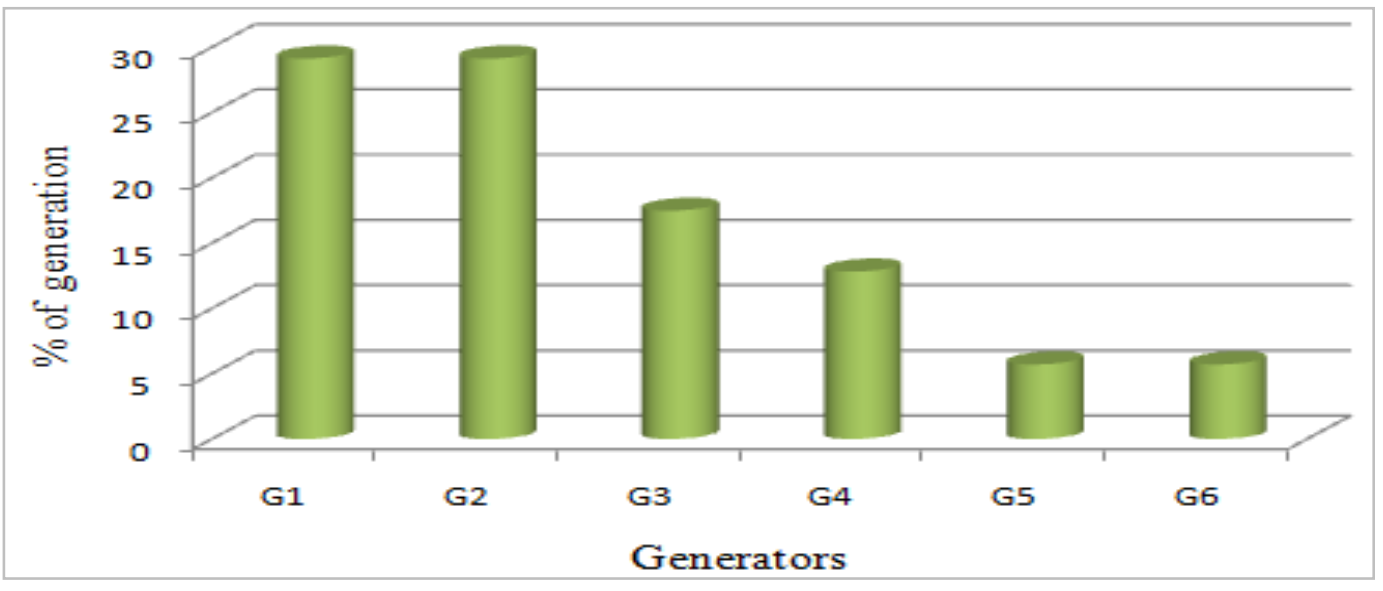

Figure 11 Percentage of energy generated in the microgrid under islanding mode operation (at 15thhour) 
Kavitha Kumari KS and Samuel Rajesh Babu R.

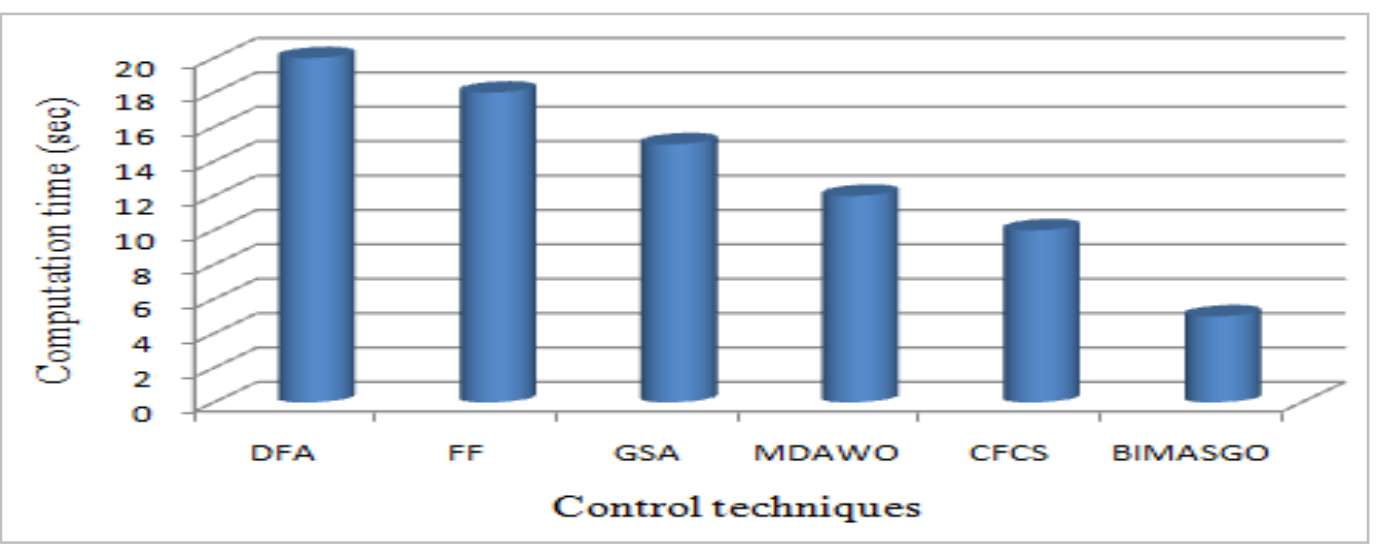

Figure 12 Computation time comparis on of proposed approach and existing approaches

Table 2 Characteristic of generating unit

\begin{tabular}{llllll}
\hline $\begin{array}{l}\text { Generator } \\
\text { type }\end{array}$ & Unit count & $\begin{array}{l}\text { Cost coefficient } \\
\mathbf{( \$ / M W h )}\end{array}$ & $\begin{array}{l}\text { Capacity of Min.- } \\
\text { max. } \mathbf{M W})\end{array}$ & $\begin{array}{l}\text { Min. up/down } \\
\text { time(h) }\end{array}$ & $\begin{array}{l}\text { Ramp-up/down } \\
\text { rate }(\mathbf{M W / h})\end{array}$ \\
\hline $\mathrm{D}$ & $\mathrm{G} 1$ & 27.70 & $1.0-5.0$ & 3 & 2.50 \\
\hline $\mathrm{D}$ & $\mathrm{G} 2$ & 39.10 & $1.0-5.0$ & 3 & 2.50 \\
\hline $\mathrm{D}$ & $\mathrm{G} 3$ & 61.30 & $0.8-3.0$ & 1 & 3.0 \\
\hline $\mathrm{D}$ & $\mathrm{G} 4$ & 65.60 & $0.8-3.0$ & 1 & 3.0 \\
\hline $\mathrm{ND}$ & $\mathrm{G} 5$ & 0 & $0-1.0$ & - & - \\
\hline $\mathrm{ND}$ & $\mathrm{G} 6$ & 0 & $0-1.5$ & - & - \\
\hline
\end{tabular}

Table 3 Characteristic of adjustable load

\begin{tabular}{lllll}
\hline Load & Min.- max. capacity $(\mathbf{M W})$ & Required energy $(\mathbf{M W h})$ & Initial start-end time (h) & Min up time (h) \\
\hline L1 & $0.0-0.4$ & 1.7 & $11-15$ & 1 \\
\hline L2 & $0.0-0.4$ & 1.7 & $15-19$ & 1 \\
\hline L3 & $0.02-0.8$ & 2.5 & $16-18$ & 1 \\
\hline L4 & $0.02-0.8$ & 2.5 & $14-22$ & 1 \\
\hline
\end{tabular}

Table 4 Scheduling of adjustable load for grid connected mode

\begin{tabular}{llllllllllllllllllllllllll}
\hline HOU & $\mathbf{1}$ & $\mathbf{2}$ & $\mathbf{3}$ & $\mathbf{4}$ & $\mathbf{5}$ & $\mathbf{6}$ & $\mathbf{7}$ & $\mathbf{8}$ & $\mathbf{9}$ & $\mathbf{1}$ & $\mathbf{1}$ & $\mathbf{1}$ & $\mathbf{1}$ & $\mathbf{1}$ & $\mathbf{1}$ & $\mathbf{1}$ & $\mathbf{1}$ & $\mathbf{1}$ & $\mathbf{1}$ & $\mathbf{2}$ & $\mathbf{2}$ & $\mathbf{2}$ & $\mathbf{2}$ & $\mathbf{2}$ \\
$\mathbf{R}$ & & & & & & & & & & $\mathbf{0}$ & $\mathbf{1}$ & $\mathbf{2}$ & $\mathbf{3}$ & $\mathbf{4}$ & $\mathbf{5}$ & $\mathbf{6}$ & $\mathbf{7}$ & $\mathbf{8}$ & $\mathbf{9}$ & $\mathbf{0}$ & $\mathbf{1}$ & $\mathbf{2}$ & $\mathbf{3}$ & $\mathbf{4}$ \\
\hline L1 & 1 & 1 & 1 & 1 & 1 & 0 & 0 & 0 & 0 & 0 & 0 & 0 & 0 & 0 & 0 & 0 & 0 & 0 & 0 & 0 & 0 & 0 & 0 & 0 \\
L2 & 1 & 1 & 1 & 1 & 1 & 0 & 0 & 0 & 0 & 0 & 0 & 0 & 0 & 0 & 0 & 0 & 0 & 0 & 0 & 0 & 0 & 0 & 0 & 0 \\
L3 & 1 & 1 & 1 & 0 & 0 & 0 & 0 & 0 & 0 & 0 & 0 & 0 & 0 & 0 & 0 & 0 & 0 & 0 & 0 & 0 & 0 & 0 & 0 & 0 \\
L4 & 1 & 1 & 1 & 1 & 1 & 1 & 1 & 1 & 0 & 0 & 0 & 0 & 0 & 0 & 0 & 0 & 0 & 0 & 0 & 0 & 0 & 0 & 0 & 0 \\
\hline
\end{tabular}

Table 5 Scheduling of adjustable load for islanded mode

\begin{tabular}{lllllllllllllllllllllllll}
\hline HOU & $\mathbf{1}$ & $\mathbf{2}$ & $\mathbf{3}$ & $\mathbf{4}$ & $\mathbf{5}$ & $\mathbf{6}$ & $\mathbf{7}$ & $\mathbf{8}$ & $\mathbf{9}$ & $\mathbf{1}$ & $\mathbf{1}$ & $\mathbf{1}$ & $\mathbf{1}$ & $\mathbf{1}$ & $\mathbf{1}$ & $\mathbf{1}$ & $\mathbf{1}$ & $\mathbf{1}$ & $\mathbf{1}$ & $\mathbf{2}$ & $\mathbf{2}$ & $\mathbf{2}$ & $\mathbf{2}$ & $\mathbf{2}$ \\
$\mathbf{R}$ & & & & & & & & & & $\mathbf{0}$ & $\mathbf{1}$ & $\mathbf{2}$ & $\mathbf{3}$ & $\mathbf{4}$ & $\mathbf{5}$ & $\mathbf{6}$ & $\mathbf{7}$ & $\mathbf{8}$ & $\mathbf{9}$ & $\mathbf{0}$ & $\mathbf{1}$ & $\mathbf{2}$ & $\mathbf{3}$ & $\mathbf{4}$ \\
\hline L1 & 0 & 0 & 0 & 0 & 0 & 0 & 0 & 0 & 0 & 0 & 1 & 1 & 1 & 1 & 1 & 0 & 0 & 0 & 0 & 0 & 0 & 0 & 0 & 0 \\
L2 & 0 & 0 & 0 & 0 & 0 & 0 & 0 & 0 & 0 & 0 & 0 & 0 & 0 & 0 & 1 & 1 & 1 & 1 & 1 & 0 & 0 & 0 & 0 & 0 \\
L3 & 0 & 0 & 0 & 0 & 0 & 0 & 0 & 0 & 0 & 0 & 0 & 0 & 0 & 0 & 0 & 1 & 1 & 1 & 0 & 0 & 0 & 0 & 0 & 0 \\
L4 & 0 & 0 & 0 & 0 & 0 & 0 & 0 & 0 & 0 & 0 & 0 & 0 & 0 & 1 & 1 & 1 & 1 & 1 & 1 & 1 & 1 & 1 & 0 & 0 \\
\hline
\end{tabular}

Table 6 Modeling metrics of established to existing method under the count of 50 and 100 trial

\begin{tabular}{|c|c|c|c|c|c|c|}
\hline \multirow{2}{*}{ Metrics } & \multicolumn{6}{|c|}{50 trails } \\
\hline & DFA & FF & GSA & MDAWO & CFCS & Proposed \\
\hline RMSE & 30.28 & 25.3 & 17.8 & 22.4 & 9.26 & 7.840 \\
\hline MAPE & 17.392 & 16.1 & 5.3 & 12.1 & 0.95 & 0.748 \\
\hline \multirow[t]{2}{*}{ MBE } & 6.783 & 6.1 & 1.8 & 4.1 & 1 & 0.9971 \\
\hline & 100 tra & & & & & \\
\hline RMSE & 31.293 & 28.4 & 22.9 & 25.5 & 7.38 & 5.21 \\
\hline
\end{tabular}




\begin{tabular}{lllllll}
\hline MAPE & 18.930 & 17.2 & 6.4 & 15.0 & 1.91 & 0.93 \\
\hline MBE & 12.37 & 11.1 & 6.9 & 7.1 & 2.87 & 1.93 \\
\hline
\end{tabular}

Table 7 Proficiency under different number of trails

\begin{tabular}{ccccc}
\hline \multirow{2}{*}{ Solution techniques } & \multicolumn{4}{c}{ Proficiency acquired under different trails (\%) } \\
\cline { 2 - 5 } & $\mathbf{1 0 0}$ trails & $\mathbf{2 0 0}$ trails & $\mathbf{5 0 0}$ trails & $\mathbf{1 0 0 0}$ trails \\
\hline Proposed technique & 99.9673 & 99.7890 & 99.89402 & 99.77879 \\
\hline CFCS & 99.0037 & 99.2356 & 99.8363 & 99.9373 \\
\hline MDAWO & 85.1948 & 88.3632 & 87.7322 & 83.4378 \\
\hline GSA & 80.3432 & 79.0342 & 77.1177 & 79.2140 \\
\hline FF & 75.6032 & 69.06723 & 65.32457 & 61.03937 \\
\hline DFA & 55.8935 & 59.84356 & 68.8362 & 60.9273 \\
\hline
\end{tabular}

\section{Conclusion and future work}

In this manuscript, a hybrid BIMASGO method for optimum microgrid programming using various restrictions of islanding mode was proposed. The proposed model is used two different operations (i) grid connected mode (ii) islanding mode. The proposed approach obtained optimal scheduling. The major purpose of the BIMASGO approach was cost minimization and power mismatch reduction. The resilience operation was ensured by the adjustment loads with ESS. Finally, the BIMASGO method was likened to the existing methods like MDAWO, DFA, FF, GSA, and CFCS. The experimental outcomes demonstrate the economic resilience benefit of the BIMASGO method. It is found to be high as compared to the existing methods.

In future a robust scenario-based optimization method can be developed to handle forecast uncertainties at optimal microgrid planning. It can be based on grid outages with the help of energy management system. In future, waste heat recovery network with joint cycle gas turbines can be analysed that link the flows of electric and thermal energy. Future studies can focus on the structured load management approaches with multiple energy networks.

\section{Acknowledgment}

None.

\section{Conflicts of interest}

The authors have no conflicts of interest to declare.

\section{References}

[1] Sefidgar-dezfouli A, Joorabian M, Mashhour E. A multiple chance-constrained model for optimal scheduling of microgrids considering normal and emergency operation. International Journal of Electrical Power \& Energy Sy stems. 2019; 112:370-80.

[2] Faridnia N, Habibi D, Lachowicz S, Kavousifard A. Optimal scheduling in a microgrid with a tidal generation. Energy. 2019; 171:435-43.
[3] Hemmati M, Mohammadi-ivatloo B, Abapour M, Anvari-moghaddam A. Optimal chance-constrained scheduling of reconfigurable microgrids considering islanding operation constraints. IEEE Sy stems Journal. 2020; 14(4):5340-9.

[4] Dong B, Jiao L, Wu J. Graph-based hybrid hyperheuristic channel scheduling algorithm in multicell networks. Transactions on Emerging Telecommunications Technologies. 2017; 28(1).

[5] Aghdam FH, Kalantari NT, Mohammadi-ivatloo B. A chance-constrained energy management in multimicrogrid systems considering degradation cost of energy storage elements. Journal of Energy Storage. 2020.

[6] Wen Y, Chung CY, Liu X, Che L. Microgrid dispatch with frequency-aware islanding constraints. IEEE Transactions on Power Systems. 2019; 34(3):2465-8.

[7] Shah P, Mehta B. Microgrid optimal scheduling with renewable energy sources considering islanding constraints. Iranian Journal of Science and Technology, Transactions of Electrical Engineering. 2019; 44:80519.

[8] Abadi M, Sadeghzadeh SM. A control approach with seamless transition capability for a single-phase inverter operating in a microgrid. International Journal of Electrical Power \& Energy Sy stems. 2019; 111:47585.

[9] Hussain A, Bui VH, Kim HM. Resilience-oriented optimal operation of networked hybrid microgrids. IEEE Transactions on Smart Grid. 2017; 10(1):204-15.

[10] Hussain A, Bui VH, Kim HM. Fuzzy logic-based operation of battery energy storage systems (BESSs) for enhancing the resiliency of hybrid microgrids. Energies. 2017; 10(3):1-9.

[11] Hussain A, Bui VH, Kim HM. A resilient and privacypreserving energy management strategy for networked microgrids. IEEE Transactions on Smart Grid. 2016; 9(3):2127-39.

[12] Balasubramaniam K, Saraf P, Hadidi R, Makram EB. Energy management system for enhanced resiliency of microgrids during islanded operation. Electric Power Systems Research. 2016; 137:133-41.

[13] Zadsar M, Haghifam MR, Larimi SM. Approach for self-healing resilient operation of active distribution network with microgrid. IET Generation, Transmission \& Distribution. 2017; 11(18):4633-43. 
[14] Hussain A, Rousis AO, Konstantelos I, Strbac G, Jeon J, Kim HM. Impact of uncertainties on resilient operation of microgrids: a data-driven approach. IEEE Access. 2019; 7:14924-37.

[15] Dong J, Zhu L, Su Y, Ma Y, Liu Y, Wang F, et al. Battery and backup generator sizing for a resilient microgrid under stochastic extreme events. IET Generation, Transmission \& Distribution. 2018; 12(20):4443-50.

[16] Gao H, Chen Y, Xu Y, Liu CC. Resilience-oriented critical load restoration using microgrids in distribution systems. IEEE Transactions on Smart Grid. 2016; 7(6):2837-48.

[17] Liu X, Shahidehpour M, Li Z, Liu X, Cao Y, Bie Z. $M i c r o g r i d s$ for enhancing the power grid resilience in extreme conditions. IEEE Transactions on Smart Grid. 2016; 8(2):589-97.

[18] Salehpour MJ, Tafreshi SM. The effect of price responsive loads uncertainty on the risk-constrained optimal operation of a smart micro-grid. International Journal of Electrical Power \& Energy Systems. 2019; 106:546-60.

[19] Chanda S, Srivastava AK. Defining and enabling resiliency of electric distribution systems with multiple microgrids. IEEE Transactions on Smart Grid. 2016; 7(6):2859-68.

[20] Bektas Z, Kayalıca MO, Kayakutlu G. A hybrid heuristic algorithm for optimal energy scheduling of grid-connected micro grids. Energy Systems. 2020:117.

[21] Gu W, Wu Z, Bo R, Liu W, Zhou G, Chen W, et al. Modeling, planning and optimal energy management of combined cooling, heating and power microgrid: a review. International Journal of Electrical Power \& Energy Systems. 2014; 54:26-37.

[22] Belvedere B, Bianchi M, Borghetti A, Nucci CA, Paolone M, Peretto A. A microcontroller-based power management system for standalone microgrids with hybrid power supply. IEEE Transactions on Sustainable Energy. 2012; 3(3):422-31.

[23] Sobu A, Wu G. Dynamic optimal schedule management method for microgrid system considering forecast errors of renewable power generations. In international conference on power system technology 2012 (pp. 1-6). IEEE.

[24] Alqurashi A, Etemadi AH, Khodaei A. Treatment of uncertainty for next generation power systems: state-ofthe-art in stochastic optimization. Electric Power Sy stems Research. 2016; 141:233-45.

[25] Carrión M, Arroyo JM. A computationally efficient mixed-integer linear formulation for the thermal unit commitment problem. IEEE Transactions on Power Sy stems. 2006; 21(3):1371-8.

[26] Khodaei A. Microgrid optimal scheduling with multiperiod islanding constraints. IEEE Transactions on Power Sy stems. 2013; 29(3):1383-92.

[27] Wang MQ, Gooi HB. Spinning reserve estimation in microgrids. IEEE Transactions on Power Systems. 2011; 26(3):1164-74.
[28] Rokni SG, Radmehr M, Zakariazadeh A. Optimum energy resource scheduling in a microgrid using a distributed algorithm framework. Sustainable Cities and Society. 2018; 37:222-31.

[29] Ebrahimi MR, Amjady N. Adaptive robust optimization framework for day-ahead microgrid scheduling. International Journal of Electrical Power \& Energy Systems. 2019; 107:213-23.

[30] Vahedipour-dahraei M, Najafi HR, Anvarimoghaddam A, Guerrero JM. Security-constrained unit commitment in AC microgrids considering stochastic price-based demand response and renewable generation. International Transactions on Electrical Energy Systems. 2018; 28(9):1-26.

[31] Kiptoo MK, Lotfy ME, Adewuyi OB, Conteh A, Howlader AM, Senjyu T. Integrated approach for optimal techno-economic planning for high renewable energy-based isolated microgrid considering cost of energy storage and demand response strategies. Energy Conversion and Management. 2020.

[32] Banaei M, Rezaee B. Fuzzy scheduling of a nonisolated micro-grid with renewable resources. Renewable Energy. 2018; 123:67-78.

[33] Gazijahani FS, Ajoulabadi A, Ravadanegh SN, Salehi J. Joint energy and reserve scheduling of renewable powered microgrids accommodating price responsive demand by scenario: a risk-based augmented epsilonconstraint approach. Journal of Cleaner Production. 2020.

[34] Kumar RS, Raghav LP, Raju DK, Singh AR. Intelligent demand side management for optimal energy scheduling of grid connected microgrids. Applied Energy. 2021; 285:1-14.

[35] Wei J, Zhang Y, Wang J, Cao X, Khan MA. Multiperiod planning of multi-energy microgrid with multitype uncertainties using chance constrained information gap decision method. Applied Energy. 2020.

[36] Kumari KK, Babu RS. An efficient modified dragonfly algorithm and whale optimization approach for optimal scheduling of microgrid with islanding constraints. Transactions of the Institute of Measurement and Control. 2021; 43(2):421-33.

[37] Sefidgar-dezfouli A, Davatgaran V. Smart microgrid optimal scheduling with stable and economic islanding capability using optimal load contribution as spinning reserve. International Transactions on Electrical Energy Systems. 2020; 30(11).

[38] Aghdam FH, Kalantari NT, Mohammadi-ivatloo B. A stochastic optimal scheduling of multi-microgrid systems considering emissions: a chance constrained model. Journal of Cleaner Production. 2020.

[39] Lee J, Lee S, Lee K. Multistage stochastic optimization for microgrid operation under islanding uncertainty. IEEE Transactions on Smart Grid. 2020; 12(1):56-66.

[40] Vahedipour-dahraie $M$, Rashidizadeh-kermani $H$, Anvari-moghaddam A, Siano P. Flexible stochastic scheduling of microgrids with islanding operations complemented by optimal offering strategies. CSEE 
Journal of Power and Energy Systems. 2020; 6(4):86777.

[41] Jafari A, Ganjehlou HG, Khalili T, Bidram A. A fair electricity market strategy for energy management and reliability enhancement of islanded multi-microgrids. Applied Energy. 2020.

[42] Lei H, Huang S, Liu Y, Zhang T. Robust optimization for microgrid defense resource planning and allocation against multi-period attacks. IEEE Transactions on Smart Grid. 2019; 10(5):5841-50.

[43] Liu Y, Guo L, Hou R, Wang C, Wang X. A hybrid stochastic/robust-based multi-period investment planning model for island microgrid. International Journal of Electrical Power \& Energy Systems. 2021.

[44] Elrayyah A, Cingoz F, Sozer Y. Construction of nonlinear droop relations to optimize islanded microgrid operation. IEEE Transactions on Industry Applications. 2015; 51(4):3404-13.

[45] Kim HM, Kinoshita T, Shin MC. A multiagent system for autonomous operation of islanded microgrids based on a power market environment. Energies. 2010; 3(12):1972-90.

[46] Debnath S, Arif W, Baishya S. Buyer inspired metaheuristic optimization algorithm. Open Computer Science. 2020; 10(1):194-219.

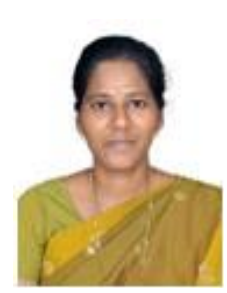

Mrs. KS Kavitha Kumari received Bachelor of Engineering Degree in Electrical and Electronics Engineering from Priyadharshini Engineering College, Anna University Chennai in 2005. Master degree with Power Sy stem Engineering from Velammal Engineering College, Anna University in 2007. Currently, she is pursuing PhD from Sathyabama Institute of Science and Technology, Chennai. Currently, she is also working as Assistant Professor in Department of Electrical and Electronics Engineering, JEPPIAAR Engineering College, Chennai. Her area of interest includes Smart Grid, Micro Grid, Flexible AC Transmission Sy stems and Power System Operation and Control.

Email: kavithakseee@gmail.com

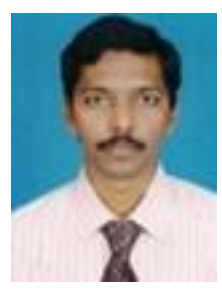

Dr. R. Samuel Rajesh Babu has obtained his B.E Degree from Madras University in 2003. He obtained his M.E degree from Anna University in 2005. $\mathrm{He}$ obtained his $\mathrm{PhD}$ degree from Sathyabama University in 2013. Presently he is working as an Associate Professor in Sathyabama Institute of Science and Technology, Chennai. His areas of interest are Power Electronics and Digital Protection.

Email: samuel.rajeshbabu@ gmail.com

\begin{tabular}{lll} 
Appendix I & \\
\hline S.No. & Abbreviation & Description \\
\hline 1 & ADMM & $\begin{array}{l}\text { Alternating Direction Method of } \\
\text { the Multiplier }\end{array}$ \\
\hline 2 & BIMA & $\begin{array}{l}\text { Buyer Inspired Metaheuristic } \\
\text { Optimization Algorithm }\end{array}$ \\
\hline 3 & CFA & Cuttlefish Algorithm \\
\hline 4 & CFCS & Cuttlefish and Crow Search \\
\hline 5 & CSA & Crow Search Algorithm \\
\hline 6 & DER & Distributed Energy Resources \\
\hline 7 & DFA & Dragonfly Algorithm \\
\hline 8 & DSM & Demand Side Management \\
\hline 9 & EMS & Energy Management Systems \\
\hline 10 & ESP & Energy storage power \\
\hline 11 & ESS & Energy Storage System \\
\hline 12 & FF & Firefly \\
\hline 13 & FLC & Fuzzy Logic Controller \\
\hline 14 & GSA & Gravitational Search Algorithm \\
\hline 15 & ISO & Independent System Operator \\
\hline 16 & MBE & Mean Bias Error \\
\hline 17 & MDA & Modified Dragonfly Algorithm \\
\hline 18 & MDAWO & $\begin{array}{l}\text { Modified Dragonfly Algorithm } \\
\text { and Whale Optimization }\end{array}$ \\
\hline 19 & MMG & Multiple Microgrids \\
\hline 20 & PCC & Point of Common Coupling \\
\hline 21 & PSO & Particle Swarm Optimization \\
\hline 22 & PSS & Probability of Self-Sufficiency \\
\hline 23 & RES & Renewable Energy Source \\
\hline 24 & RMSE & Root Mean Squared Error \\
\hline 25 & SGO & Shell Game Optimization \\
\hline 26 & WOA & Whale Optimization Algorithm \\
\hline & & \\
\hline 13 & \\
\hline 19 &
\end{tabular}

